\title{
Pandillas y conflicto urbano en Colombia
}

\author{
Carlos Mario Perea Restrepo
}

Las pandillas proliferan en todo el mundo. Su forma de habitar la localidad, a través del ejercicio de una cruda transgresión violenta, las ha puesto en el centro de la preocupación sobre la seguridad en la ciudad. La pandilla acude a la criminalidad y administra la violencia, no cabe duda. No obstante, la mirada y la tramitación del conflicto urbano no pueden desconocer a los otros actores partícipes de las guerras de pavimento: los vecinos organizados en defensas urbanas, las operaciones de limpieza, los actores armados, la delincuencia y hasta la policía. Esta otra cara, donde queda comprometido el fundamento mismo de la institucionalidad, suele ser olvidada. Mediante la mirada a tres ciudades colombianas, el artículo aborda entonces el papel y las formas de operación de dos de estos otros actores de la conflictividad urbana: los vecinos y las operaciones de limpieza.

Gangs have been proliferating all over the world. Their way of inhabiting the locality, by exercising crude violence, has placed them at the core of concern about safety in cities. There is no doubt that gangs take to criminality and commit acts of violence. However, the ways of seeing and dealing with urban conflict cannot disregard the other actors participating in the sidewalk war: neighbors organized in urban defense; crackdown operations, armed actors, criminals and even the police. This other side, where the very foundations of institutionality are involved, is often forgotten. By looking at three Colombian cities, this article seeks to understand the role and means of operation of two of the actors of conflictiveness in the city: neighbors and crackdown operations.

CARLOS MARIO PEREA RESTREPo: Universidad Nacional de Colombia.

Desacatos, núm. 14, primavera-verano 2004, pp. 15-35. 
C omo sucede con varias expresiones de identidad, en particular entre los jóvenes, la pandilla se desparrama por el planeta. La adoptan multiplicidad de muchachos en países centrales y periféri$\cos$, ricos y pobres, grandes y pequeños. Salta por encima de la riqueza y la penuria, del bienestar económico y el atraso industrial implantándose en la barriada de Latinoamérica y África, pero igual prolifera hacia el norte en la metrópoli industrializada.

Su núcleo duro la acompaña, brinca del rincón de aquí al de allá lejos; mas su fisonomía particular se cincela en función del conflicto nacional y urbano donde nace y crece. ${ }^{1}$ En las naciones industrializadas la pandilla se caracteriza por el antagonismo entre la abundancia y la injusticia mundial, vestido de racismo y xenofobia. En Europa y Estados Unidos, las pandillas suelen arroparse con el signo étnico, unas conformadas por inmigrantes; otras, por "blancos" dispuestos a hacer valer su pretendida supremacía racial. ${ }^{2}$ En Sudáfrica se revisten de su pasado reciente, la renovada emergencia de la criminalidad después de la caída del apartheid y el inicio de un gobierno autónomo. ${ }^{3}$ En Latinoamérica, por su parte, se riegan ligadas al incremento de la exclusión y la miseria. En Centroamérica abundan con prominente fuerza en El Salvador, ${ }^{4}$ mientras otro tanto sucede en México ${ }^{5}$ y en algunos países

\footnotetext{
${ }^{1}$ El núcleo duro de la pandilla hace referencia a la mezcla de juventud, tiempo paralelo y territorio dominado: la pandilla es una experiencia juvenil que rompe los ritmos de la vida corriente — se la pasan de día entero en la esquina, ajenos a cualquier actividad socialmente productiva-, sobre la base de dominar un territorio. Tal núcleo duro se encuentra regado por el mundo, más la forma e intensidad de su presencia y dominio se modelan en función del país y la ciudad donde viven. ${ }^{2}$ En Alemania asume formas neonazis, Funke (2000). En Francia, la película El odio retrata los inmigrantes norafricanos. Para una mirada anterior de las pandillas francesas, véase el clásico libro de Monod (2002) y una reciente en Roché (2003). Respecto a Estados Unidos, en lo que se refiere a las pandillas de la ciudad de Los Ángeles, véase Bourgois (1995) y de Boston, Kennedy, Braga y Piehl (2003). Un clásico de los estudios de la escuela de Chicago, en Whyte (1971).

${ }^{3}$ Chabedi (2002).

${ }^{4}$ Sobre Centroamérica hay una rica producción cuyo mejor texto es Equipo de Reflexión y colaboradores (2001), donde se contemplan El Salvador, Guatemala, Honduras y Nicaragua. Además, sobre El Salvador véase Homies Unidos y colaboradores (1998) y Santacruz y Concha (2001); sobre Nicaragua, Rodgers (2002 y 2000) y Liebel (2002).

${ }^{5}$ Hacia comienzos del siglo XXI la situación de México y sus pandillas se ha transformado de manera notable. Los chavos bandas, como se les llama, dejaron de ser un fenómeno masivo regado en los barrios populares;
}

de Sudamérica. ${ }^{6}$ En Colombia, nuestro país de interés, se difunden en ciudades grandes y pequeñas, disparadas por la creciente pobreza y el inclemente conflicto interno.

Pretendemos acercarnos a la realidad pandillera de tres ciudades colombianas: Barranquilla, Neiva y Bogotá. Neiva es una ciudad pequeña, apenas si llega a los 300000 habitantes. Su importancia estratégica es notable, no sólo por su condición de centro cultural y económico de la región suroriental sino por su ubicación respecto a la zona de los llanos y la selva, enclave donde se libra una decisiva batalla del conflicto armado. Con razón la gente le llama "la puerta del sur". Con 1200 ooo personas, Barranquilla posee el título de cuarta ciudad nacional y primera de la costa del Caribe. Pese a su postrada economía no abandona aún su papel de polo de atracción para las migraciones internas del área costera. Por último Bogotá, capital y centro de la actividad nacional, poblada con algo más de seis millones de almas, continúa en la espiral de concentración de los recursos nacionales dando al traste con el singular crecimiento de varias ciudades que caracterizó al país. ${ }^{7}$

En las tres ciudades las pandillas proliferan. Así sucede en Barranquilla. En una zona del suroccidente de la ciudad se estableció la existencia de 44 bandas activas. ${ }^{8}$ Tal cantidad, al lado de otras 22 inactivas en el momento de la contabilización, pone bien en claro la fuerza de la presencia pandillera en la capital del Caribe. Sólo un barrio

ahora se da una compleja conexión entre los jóvenes, la criminalidad organizada y los organismos de seguridad del Estado. Literatura sobre los primeros chavos banda puede verse en León (1984), Gomezjara et al. (1987), Subdelegación de Desarrollo Social (1987), Castillo, Zermeño y Ziccardi (1988); una investigación más reciente es la de Urteaga (2000). Asimismo, está el trabajo sobre comunicación de Reguillo (1991) y el de los pachuchos de Valenzuela (1988).

${ }^{6}$ Sobre Ecuador véase Andrade (1994). Un texto que trata el fenómeno en varios países es el de Briceño-León (2003), donde se relatan experiencias pandilleras de Brasil, Ecuador, Venezuela, El Salvador y Colombia.

${ }^{7}$ Colombia es el país latinoamericano que gozó de un desarrollo paralelo de cuatro ciudades, en contraste con el agigantado crecimiento de una sola, como es el caso extremo de la ciudad de México. Que la tendencia se viene revirtiendo desde los años 1970, lo muestra la crisis en Medellín, Cali y Barranquilla. Una rica discusión al respecto puede verse en Gouëset (1998).

${ }^{8}$ En las tres ciudades se seleccionó una zona popular con elevados niveles de conflicto. 


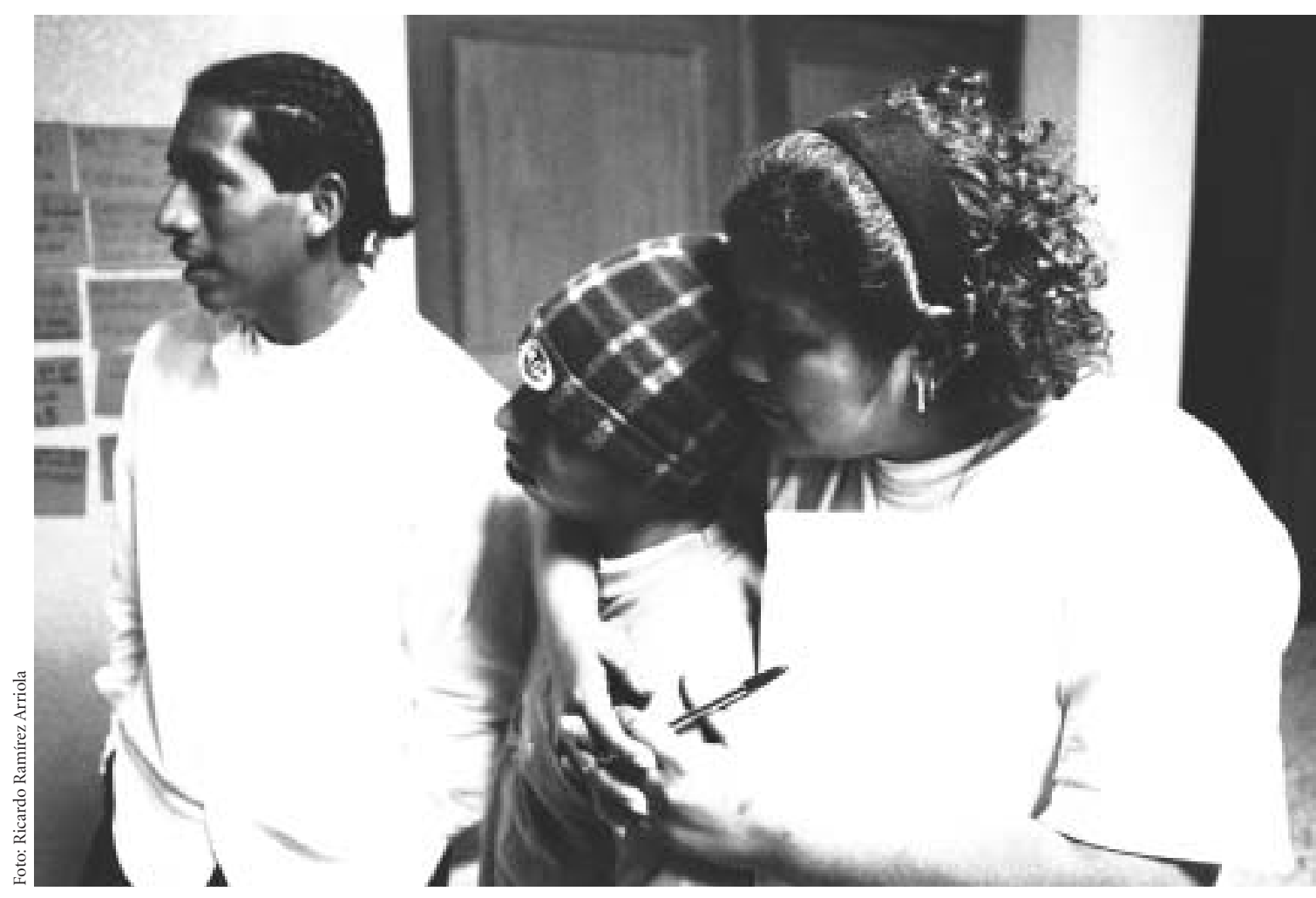

"Aquí estás viendo que habemos de la MS y de la 18. Juntar miembros de las dos pandillas es algo que casi no se logra. Hasta ahora no era normal."

Las fotos de Ricardo Ramírez Arriola fueron hechas en abril de 2004, durante el segundo taller para promotores juveniles organizado por la Procuraduría de Derechos Humanos de Guatemala, apoyado por USAID y Creative Associates International. El proyecto busca prepararlos para su trabajo como promotores y ha reunido — hecho inusual — a jóvenes que provienen tanto de la Mara Salvatrucha, de la 18 y de la calle.

estratégico por su antigüedad y tamaño, habitado por 48000 personas, registró 11 pandillas. Los reportes oficiales confirman la situación, $46 \%$ de los hogares barranquilleros experimenta el acoso pandillero como un problema cercano a su sitio de vivienda. ${ }^{9}$ En Neiva sucede otro tanto. En el suroriente se contabilizó un total de 25 parches. Por su parte, en Bogotá el cuadro es similar; en el área delimitada en el suroriente se identificaron 45 pandillas. Los registros oficiales también lo corroboran, $54 \%$ de los hogares bogotanos reconoce en las pandillas un problema vivido en carne propia. ${ }^{10}$

\footnotetext{
9 DANE (1995).

10 DANE (1995).
}

No sólo por su cantidad sino también por su manera de habitar el barrio, el pandillero no pasa inadvertido. Todo lo contrario, impone su ley tornándose notorio, remarcando a cada instante su determinación violenta. En este empeño construye un poder socialmente eficaz, ejerce un dominio sobre la esfera pública local desatando un conflicto con diversos actores. Los muchachos neivanos lo dirán: "Los enemigos del parche son la ley, el vecino sapo, los paracos y algunos parches." 11 El espectro es

\footnotetext{
${ }^{11}$ Caballo, Neiva, p. 9. Los nombres de los parceros han sido cambiados por razones de seguridad. Las frases entrecomilladas corresponden a textos literales extraídos de sus historias de vida. Estas historias no están publicadas pero se encuentran archivadas en la biblioteca del Instituto de Estudios Políticos y Relaciones Internacionales de la Universidad
} 


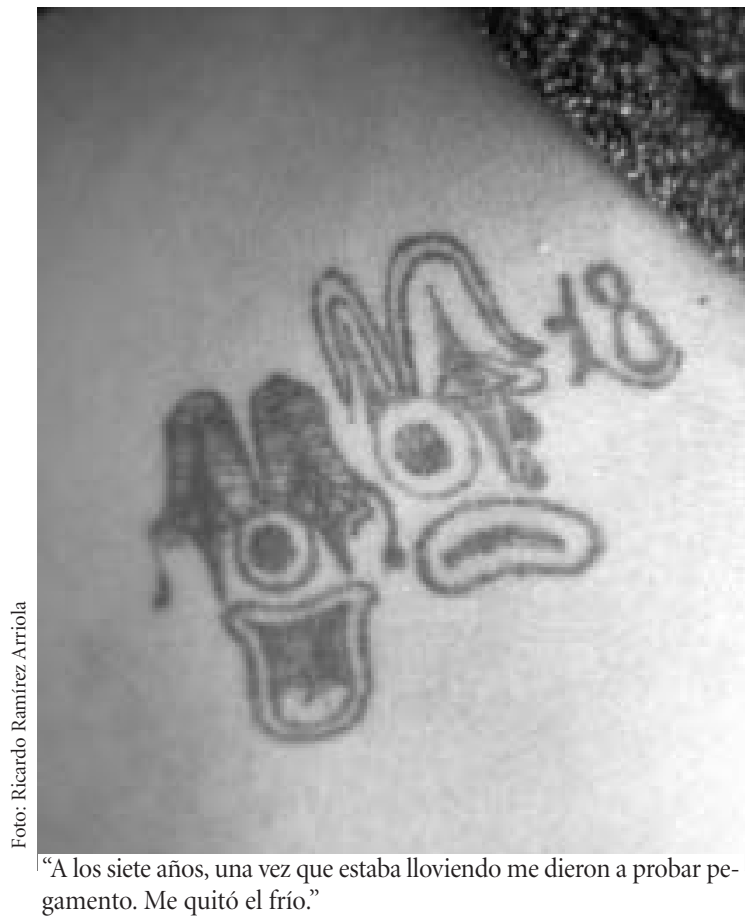

extenso, va de la policía a los grupos armados pasando por los vecinos y otras pandillas.

Dicho en breve, la transgresión pandillera cobra vida dentro de las guerras de pavimento, enfrentamientos violentos escenificados en el asfalto de las calles de la ciudad. La visagra de tales hostilidades se arma de múltiples articulaciones, en parte ligadas a los conflictos nacionales, en parte remitidas a las gramáticas de la vida diaria en el vecindario. El sostenido uso de la transgresión violenta por parte de la pandilla aviva a sus contradictores. Los vecinos reclaman la restitución de la convivencia, mientras que las operaciones de limpieza intentan imponer un orden mediante el asesinato descarnado; otras pandillas se trastocan en enemigos irreconciliables, tantas veces hasta el exterminio; la policía se convierte en portadora del rechazo visceral producido por el afuera pandillero,

Nacional de Colombia. Parche es la palabra con la que los mismos pandillos designan la pandilla y parcero es el compañero; sapo es un soplón, un "madrina"; paracos es paramilitares, un ejército de enorme fuerza en Colombia.

al tanto que guerrillas y paramilitares se entrecruzan con los parceros en caminos paradójicos, unas veces como partícipes del intento de imponer una "legalidad"; otras, hermanados con la rebelión pandillera. Las fuerzas van y vienen, absorbidas en una espiral donde el pandillero opera como un centro de reciclamiento del conflicto urbano.

En estas páginas nos ocuparemos de este conflicto. Los pandilleros se convirtieron en centro de la inseguridad, se los estigmatiza y persigue bajo el pretexto de su protagonismo violento. No cabe duda, la pandilla es capaz de sevicias sin cuento; mas el intento de depositar en ella la creciente criminalidad no es sino un estigma encaminado a aliviar el miedo que se ha apoderado de la conciencia ciudadana en la ciudad. Así es; en Colombia, nación de la ilegalidad y la violencia, la pandilla nace y se alimenta de una trama sostenida por un abigarrado elenco de actores. Los pandilleros delinquen, pero lo hacen mediante prácticas que están lejos de agotar el crimen, y violentan, pero con idéntica intensidad a la de sus adultos inmediatos. ${ }^{12}$

Nos ocuparemos entonces del otro lado del conflicto, el que siempre aparece soslayado y encubierto: ${ }^{13} \mathrm{el}$ de los adversarios de la pandilla, en particular los vecinos, con sus variadas formas de defensa, y las operaciones de limpieza con sus estrategias siniestras. Seguiremos un recorrido en tres pasos. En un primer momento se considerará la naturaleza local de la pandilla, origen del enfrentamiento; después se mirarán las reacciones de los vecinos; luego, las acciones de las operaciones de limpieza. La pandilla es un actor del conflicto urbano contemporáneo. Para entenderla, no obstante, no se puede hacer al margen de los personajes que se le oponen, personajes investidos con la complicidad del Estado y sus organismos de seguridad.

\footnotetext{
12 Su robo es básicamente el atraco callejero, el saqueo de casas y el asalto a comercios menores; sus relaciones con el crimen organizado son esporádicas y no tienen vínculo con muchas otras formas, como la criminalidad de cuello blanco. De igual modo entre los años de 1994 y 2000 en Barranquilla, Neiva y Bogotá — las tres ciudades de nuestro interés-, los jóvenes de 15 a 24 años cometieron $32 \%$ de los homicidios mientras que los adultos de entre 25 y 34 años cargaron con $30 \%$. Medicina Legal y Ciencias Forenses.

${ }^{13}$ Este artículo forma parte de un libro en marcha. No pretende dar una visión panorámica de las pandillas colombianas sino tocar un punto en particular: los enemigos de las pandillas y sus acciones. La importancia política de ello está fuera de toda duda.
} 


\section{LOCALIDADY PODER}

La pandilla es local, es una estructura afectiva construida en el intercambio diario. Asumiendo el poder como el dominio ejercido por un actor sobre la circulación de bienes estratégicos para la vida de un colectivo - sean bienes materiales o simbólicos-, el mando pandillero arranca de su condición territorial. Su identidad se afirma desde un espacio geográficamente circunscrito. Una gran cantidad de agrupaciones barriales portan consigo el marbete comunitario, lo cual significa la pretensión de incidir sobre la vida local a partir de la consideración de un espacio, sea la cuadra, el barrio o la zona. El pandillero participa de este signo pero desde el horizonte opuesto. Su norte no es alguna imagen de la vida buena — como sucede entre los grupos comunitarios-, sino un territorio delimitado por la materialidad de estas y aquellas cuadras: el grupo manda de esta calle a la de más allá.

Dentro de tal territorio se establece un orden al imponer potestad sobre bienes allí existentes, siguiendo una doble ruta. De un lado, hacia fuera, se impide la circulación de cualquier "extraño", en particular los miembros de otras pandillas, en general los vecinos impedidos para caminar la calle después de determinada hora. Quien recorre el área lo hace con la anuencia del parche, so pena de soportar el castigo que trae la violación de una regla por todos conocida. Del otro, hacia dentro, la pandilla controla intercambios estratégicos. Interfiere la libre circulación de los comercios: entorpecen la compra en los negocios de quienes tienen alguna desavenencia con el parche, los camiones repartidores se abstienen de entrar en zonas reputadas como peligrosas, las tiendas suelen convertirse en blanco de asaltos esporádicos. La interferencia no es sólo comercial, se extiende hacia la intimidad de la elección amorosa: las mujeres del territorio se asumen como "propiedad" indiscutida, impedidas para trabar vínculo con hombres de pandillas enemigas y en el peor de los casos con "desconocidos". Las fiestas y la ocupación de calles y espacios comunales caen bajo el juicio de su mirada vigilante. Las instituciones operan en función de sus prácticas, incluso los organismos de seguridad median su presencia en función de la peligrosidad de la pandilla.
El territorio se acota, tanto el vecindario como los enemigos conocen sus límites precisos. Aníbal, un pandillero barranquillero, lo cuenta: "Cuando iba llegando a mi casa los negros estaban ahí, uno me llamó diciéndome 'estoy en tu territorio, si me pisas aquí te mato.' Las maneras como se establecen los límites no siguen una pauta fija. Cada grupo busca su rincón, "los de allí tienen su plazoleta, los de esa calle en la esquina, los de acá en el billar". Desde el parche, el lugar de encuentro y reunión, el señorío se extiende sobre un puñado de cuadras. Hace un tiempo se poseían espacios extensos, en ocasiones hasta barrios enteros. La creciente fragmentación de las pandillas, en particular en las ciudades grandes, se tradujo en su proliferación y por lo tanto en la reducción de las áreas susceptibles de control. "El territorio mío era como de cinco cuadras", dice Aníbal, haciendo eco a la afirmación escuchada de manera corriente. En efecto, por lo general, el territorio no sobrepasa unas cuantas cuadras pues de este lado está otra pandilla y más allá la siguiente. ${ }^{14}$

Casi siempre la colonización del espacio se hace a partir de la agregación de muchachos que viven en las cuadras objeto de dominio; pero no es el único caso, en oportunidades se juntan jóvenes de cuadras inconexas. Sin embargo, la pertenencia barrial es clave; finalmente el territorio es arraigo, lugar donde se nace, se crece y se arma la experiencia. En medio de enormes tensiones, incluso los vecinos reconocen dicha condición: "Cada uno tiene su territorio, si ellos vienen a parcharse aquí la gente no los deja porque les echa la policía." Allí se ancla la "legitimidad" de la ley pandillera, en el yo soy de ahí invocado con frecuencia. La pertenencia a ese pequeño rincón del mundo permite que el pandillo se abrogue el derecho de imponer su minúsculo proyecto de orden. En palabras de uno, "los Nazi, los que viven dos cuadras más adelante, no pueden pasar a estos lados ni nosotros a aquéllos porque se forma la berraca". La ley es inquebrantable, adquiere el estatuto de canon inviolable pues "nunca nos dejamos sabotear el territorio porque pa' nosotros era sagrado". 15

\footnotetext{
${ }^{14}$ Aníbal, Barranquilla, p. 8; Oso, Neiva, p. 35.

${ }^{15}$ Oso, Neiva, p. 35; Mechete, Barranquilla, p. 9; Aníbal, Barranquilla, p. 13. La berraca es una pelea fuerte.
} 
Ciertamente el territorio [es] sagrado. Puesto que ahí parchan, el vecindario es el teatro donde se pasa el tiempo, trastocado en epicentro de poder. Si allí se despliega la ley pandillera, ahí mismo surgen algunos de sus más acérrimos contrincantes, las otras pandillas y los vecinos. Pero no faltarán otros actores conectados a los vecinos y las instituciones, como las operaciones de limpieza. Nos ocuparemos, uno a uno, de estos dos archienemigos de la pandilla.

\section{VECINOSY DEFENSAS URBANAS}

El vínculo del pandillo con la comunidad es problemático. Con frecuencia se le escucha decir que "no robamos en el barrio, vamos por allá a otro lado”. En ocasiones la máxima de cuidado con los vecinos se cumple, se abstienen de asaltar a la gente que circula por las calles próximas. En tales casos la pandilla deriva en agente protector, en especial cuando hace de custodio frente a las correrías de las pandillas de otros lados. "Nosotros mismos somos autodefensas porque defendemos el barrio cuando vienen a joderlo otros", dice un currambero. El papel de gendarme comunitario, no obstante, no suprime las tensiones. Por definición la pandilla es un parche, un agregado incómodo cuya presencia se verifica a fuerza de la notoriedad de su exceso: la palabra con la que se autoreconoce, el parche, no es gratuita. Ya su sola permanencia sostenida en la esquina, frente a la casa o la tienda, echa por tierra cualquier pretensión de intimidad de las gentes de la vecindad. Su escenario natural es la calle, de frente al otro, lugar donde discurre una vida sazonada con más de una euforia. Un día cualquiera las fiestas con gran algarabía pueden prolongarse hasta altas horas de la noche, en especial cuando se corona un buen trabajo: "Cuando lo pegamos firme nos hacemos el fiesto en el barrio, porque no nos vamos a ir pa' otro barrio. Se forman los problemas porque hay harto agite." 16

El conflicto con el vecindario es inevitable, forma parte de la gramática pandillera. Mas la situación se pone a otro

${ }^{16}$ La primera y tercera frases son de Gomelo, Neiva, p. 13; la segunda de Mechete, Barranquilla, p. 14. Lo pegamos firme es un buen robo. precio cuando cunde el desmadre. Los asaltos, sean de los pandilleros del barrio o de zonas aledañas, cortan el acceso a servicios claves como el transporte público o el suministro de bienes de consumo básico como la leche, las gaseosas, la cerveza: "Estamos desesperados porque los colectivos no suben hasta acá debido a la delincuencia, cada noche atracan cuatro o cinco", denuncia una edil de Neiva. Los excesos pueden llegar a extremos intolerables: "Se emborrachaban y empezaban a hacer tiros, todos con su revólver lo explotaban a la hora que fuera." Las anécdotas de golpizas y asesinatos, de violaciones y acosos aparecen de continuo en las narraciones de la gente, junto a los temores de los padres que ven en la pandilla la perdición de sus hijos, niños y jóvenes que por su corta edad son presas fáciles del juego de luces desplegado por el poder parcero. ${ }^{17}$

La pandilla provoca el desgarramiento de la pertenencia comunitaria y su potente imaginería popular de la convivencia. Un líder comunal de Barranquilla lo dirá: "Una cosa es que venga un desconocido a hacer daño aquí y otra que al tipo que todo el mundo conoce hay que cerrarle la puerta porque llegó."18 La disyuntiva es terminante, el tipo que todo el mundo conoce porque forma parte de la comunidad se vuelve un dolor de cabeza insoportable: la tensión sube hasta generar diversas iniciativas encaminadas a emplazar la desazón. Algunas, ciertamente las menos, pasan por una acción individual. Otras, la gran mayoría, congregan las energías colectivas bajo la forma de prácticas donde se combina una variopinta gama de estrategias legales e ilegales.

Unos vecinos, fastidiados con la vocinglería, intentan soluciones particulares. Algunos deciden quebrar el código espacial sobre el que se asienta el parche: "Se parchaban en la esquina hasta que el cucho los desterró. A un andén le echaba aceite y el otro lo tumbó, donde nos parchábamos a jugar dominó. Era mucha risa y recocha, el cucho decía que ya no podía ni ver un noticiero." Aunque es poco frecuente, se llega a escuchar la historia de moradores que se llenan de arrestos, toman un arma y

${ }_{17}$ Olimpa, Neiva, p. 2; Mundano, Neiva, p. 61. Lo explotaban es disparar el revólver.

18 Yepes, Barranquilla, p. 16. 


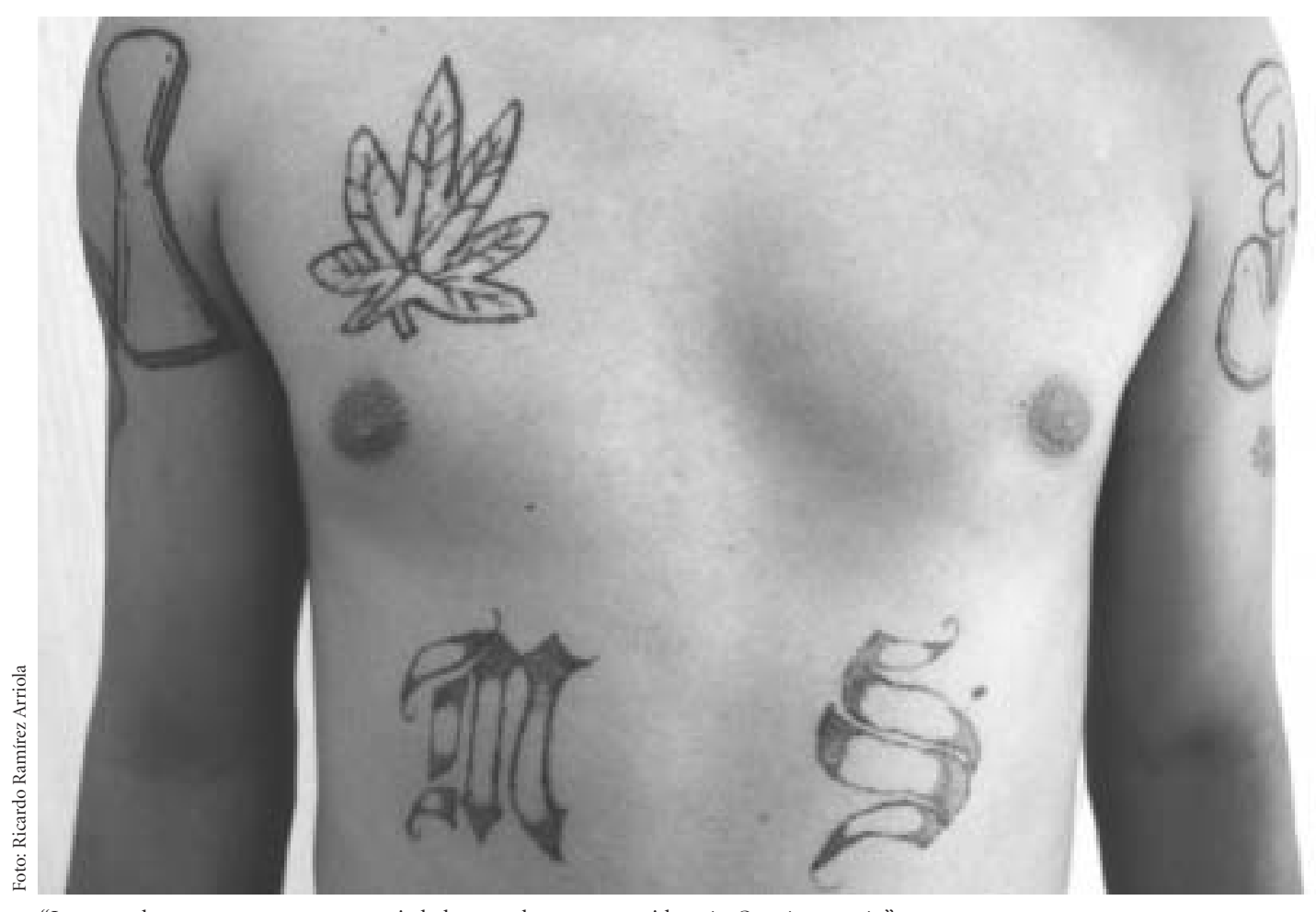

"La segunda vez ya no, ya era una ansiedad como droga que te pide más. Quería ver más."

salen a liquidar a cuanto pelao se encuentre en las esquinas: "Había un cucho que salía sólo con su fierro y al que encontrara metiendo bareta lo tumbaba, un cucho de 50 años", cuenta uno. "Aquí en el barrio hay persecución de vecinos. Uno estaba ahí y le daban plomo, hay mucha gente armada. Se da el caso de que pelados se den plomo con un señor del barrio", agrega otro. ${ }^{19}$ Algunos pescan en el río revuelto de un sórdido mercado de la muerte, vecinos ardidos que, impedidos para emprender una venganza por su propia mano, contratan un sicario que sane la pérdida de un ser querido, la violación o embarazo de una hija o cualquier otra afrenta. Sea cual sea la modalidad, tales estrategias individuales son poco corrientes. Hay que refrescarlo, la pandilla administra un terror que pocos pueden desafiar de manera personal y directa.

${ }^{19}$ Mundano, Neiva, p. 58; Richard, Bogotá, p. 35; Bernardo, Bogotá, p. 20. Cucho es adulto; recocha es molestar y hacer ruido; fierro es arma de fuego; bareta es marihuana, mota.
Las prácticas colectivas son las más comunes, las adop$\tan$ vecinos de una y otra ciudad. Las hay de dos tipos. En un polo están aquellas que pasan por los canales instituidos de tramitación del conflicto: van de la denuncia judicial y la presión sobre las autoridades a fin de que tome cartas decididas en el asunto, a la constitución de destacamentos de vigilancia en connivencia con los cuerpos de seguridad del Estado. Mientras tanto, en el otro polo caen las prácticas situadas al margen del procedimiento sancionado, aunque en su gran mayoría avaladas por la complicidad del Estado y sus agentes: desde cuerpos de autodefensa con acciones punitivas sobre los pandillos, que pueden ser de los mismos vecinos o de agentes externos contratados para el efecto, hasta las infaustas operaciones de limpieza.

De continuo, las autoridades de la ciudad y la policía reciben quejas de los vecinos. Adoptan la forma de memoriales firmados por los habitantes de un sector, generalmente movilizados por los moradores inmediatos al 

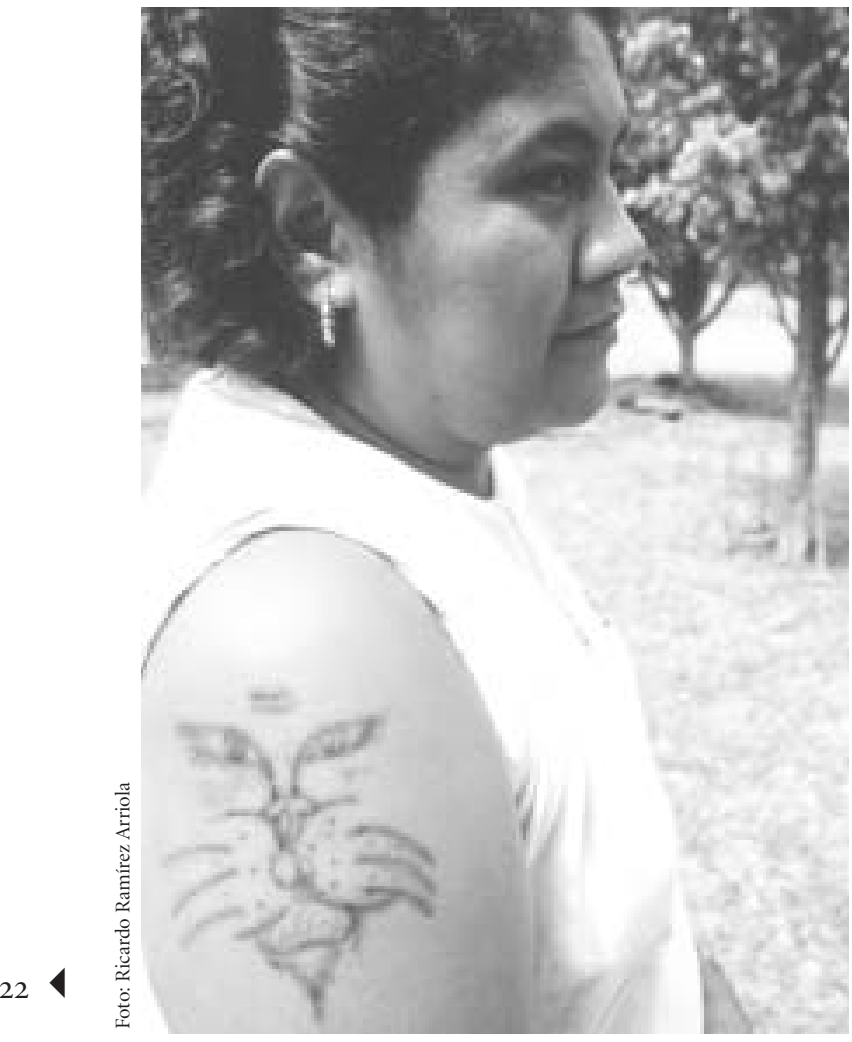

"Poder echarle la mano a alguien cuando lo necesita es algo que te llena, te hace sentir útil. Es algo que en la sociedad que se cree normal no se da."

parche: "El pueblo no lo quería, tenía muchas denuncias y firmas del barrio", se cuenta de un grupo en dificultades con los habitantes de la calle donde se paraba. El intento de contención de la pandilla suele comenzar con alguna medida dentro del mismo barrio, como ha sido el caso de la instalación de alarmas en las casas a fin de alertar sobre cualquier anomalía: "En el barrio hay alarmas comunitarias. Eso no sirve, cada rato se la escucha y nunca cogen a nadie. Al principio uno le comía, creía que todo el mundo lo va a linchar pero no, puro azare." Medidas como éstas resultan ineficaces -el pandillo lo dice-, estrelladas contra la realidad de muchachos que conocen el barrio y sus intimidades. Entonces se acude a las gestiones ante el Estado, muchas veces con las personas encargadas de la seguridad ciudadana: "Al inicio de año tuvimos varias reuniones con la secretaria de gobier- no y con el comandante de la policía comunitaria. Les dijimos que no teníamos nada más que hacer."20

Ante la prolongación de la situación —el ciclo se reproduce una y otra vez, de una ciudad a otra-, los vecinos impotentes optan por una medida radical, la realización de un paro cívico contra la inseguridad y sus principales auspiciadores locales, las pandillas. Fue el caso de Neiva, donde los vecinos de la comuna tomaron las calles protestando contra la indolencia de las autoridades ante el grave problema de la convivencia local. Como acontece casi siempre ante tales reclamos, reconocidos políticos de la ciudad se desplazaron presurosos a firmar un acuerdo con el compromiso de contener la zozobra. Pasado un corto tiempo los habitantes del barrio ven el fracaso de su protesta, la policía no emprendió ninguna acción más allá de un periodo de sostenido asedio a las pandillas. La intranquilidad sigue y se vuelve a plantear el tema de un nuevo paro cívico: "Estamos preocupados porque se hizo un paro cívico, tocará volver a hacerlo. La policía sabe donde están ellos pero les falta estrategia." El nuevo paro no se efectuó, pese a que se le comenta con insistencia, en parte porque los líderes comunales presionaron al Concejo de la ciudad para que los recibiera con el fin de discutir la situación de la zona, con especial énfasis en la inseguridad y las pandillas. ${ }^{21}$

Ante este incesante ir y venir, con resultados tan precarios, el vecindario decide convertirse en agente activo del problema. En una de sus formas se arma un dispositivo de vigilancia en vínculo directo con la policía. Aprovechando la proximidad con algún miembro de los cuerpos de seguridad un grupo hace rondas por las calles dotados de un radio conectado a la estación más cercana: "Constituimos un comité de vigilancia privada, ellos tenían armas de fuego y nosotros nada. Un sargento del Bosque nos facilitó unos radios, cuando empezábamos a notar algo llamábamos y venía la patrulla." Junto a la modalidad de un organismo privado han comenzado a proliferar las policías comunitarias, también llamadas cívicas. En las tres ciudades multitud de experiencias

${ }^{20}$ Caballo, Neiva, p. 16; Olimpa, Neiva, p. 16.

${ }^{21}$ Los informes locales ante el Concejo en Comuna 8 (s.f.). 
aparecen en uno y otro barrio, promovidas y respaldadas por las respectivas oficinas municipales de policía comunitaria. Los vecinos toman la iniciativa —o los promotores institucionales los animan-, después de lo cual viene el proceso de entrenamiento, organización y dotación de los instrumentos para actuar como apéndices informativos del cuerpo policial.

La policía comunitaria forma parte de la gran cantidad de esfuerzos descargados sobre los sectores populares ante la imposibilidad de resolver desafíos primordiales de la vida colectiva. El Estado, impedido para encararlos, traslada parte de la carga sobre los hombros de la participación popular. La lista es interminable, pasa por soluciones de vivienda; arreglo de bienes de consumo colectivo como calles, alumbrado y parques; construcción de puestos de salud y escuelas; creación de centros de atención a los menores; desarrollo de actividades culturales $y$, naturalmente ahora, esquemas contra los atentados a la convivencia. En cada caso, con proporciones variables de uno a otro, la comunidad pone una parte y el Estado otra. La policía cívica se apoltrona en esta vieja tradición de intercambio entre el Estado y las barriadas, agenciada sobre la promesa de una tranquilidad asegurada por la vigilancia vecinal, de un lado, y la pronta y eficaz presencia policial del otro.

En medio de este cuadro de intercambios entre el Estado y los sectores populares las policías comunitarias son, no obstante, un caso especial. En otros tantos programas aflora el conflicto, sea por la presencia de aspiraciones encontradas, sea por el intento de apropiación de recursos o cualquier otro motivo que trabe en contradicción intereses antagónicos. De manera distinta la participación en la vigilancia, por definición, pone en juego un potencial de elevada conflictividad: opera sobre acontecimientos en extremo delicados, los delitos contra el patrimonio y su sentido de la propiedad privada, los delitos contra la vida y su sentimiento de vulnerabilidad de la integridad. En tales condiciones, desde una de sus aristas, la policía comunitaria compromete el imaginario comunal en aras del bien común, un vivo sentir ligado a una ancestral tradición popular: "Nos toca tomar conciencia para formar un movimiento cívico que acoja todos los grupos comunitarios. Solos no vamos a ser capaces de nada", dice una de las iniciadoras de la vigilancia local. Empero, desde otro ángulo, el imaginario se ve jalado por la fidelidad hacia las personas del núcleo comunal y familiar, otro sentir de gran valía. Como dice un pandillero: "Hay gente que dice que nos dejen tranquilos, que antes nosotros cuidamos esos callejones oscuros." La contradicción se va al extremo cuando entran en pugna sentimientos familiares: "Hay gente que desafortunadamente su hijo es drogadicto. Vienen los problemas porque si mi hijo está haciendo daño a la sociedad y no lo divulgo estoy siendo cómplice. Esa es la debilidad, eso acabó con la policía cívica." En efecto, el traspaso de funciones policiales al interior del barrio enfrenta a los vecinos ante la compleja tramitación de hechos violentos. Más aún, la transgresión pandillera arrincona al vecindario. Amenaza a quienes forman parte de las policías barriales, "a uno de los compañeros quisieron atacarlo", evidenciando la dificultad de combatir a unos muchachos conocedores del barrio y sus secretos: “Tenían claves como un silbido para informarse que venía la policía. Se esfumaban, como estos patios estaban sin cercar se metían por un lado y salían a la otra calle." Y para el pandillo, por su parte, los grupos de vigilancia no hacen sino exacerbar su ansia de poder: "Armaron una vez la policía cívica pero no sirvió pa' nada. No se metían con nosotros porque saben que tienen hermanos, familiares, hijos." 22

El trámite violento está a la mano: "Los daños que estaban produciendo herían mucho a las familias hasta que hubo gente que dijo 'esto no puede ser más, que los maten'. Y a todos los han matado, la inseguridad se acabó”, cuenta un líder comunal barranquillero. ${ }^{23} \mathrm{Si}$ el trámite legal ante el Estado resulta infructuoso queda abierto el camino a la organización de destacamentos de defensa. El calificativo posee en Colombia un largo y atormentado historial. Las autodefensas se remontan a la violencia de mediados del siglo XX, cuando los campesinos se organizaron en grupos armados dispuestos a defender a su gente y sus haberes del hostigamiento militar de diversos

${ }^{22}$ La primera y la tercera cita son de Olimpa, Neiva, p. 10 y 8 ; la segunda y la quinta de Gomelo, Neiva, p. 18 y 13; la cuarta de Yepes, Barranquilla, p. 16.

23 Yepes, Barranquilla, p. 16 
adversarios. ${ }^{24}$ Incluso el más remoto origen de la guerrilla de las FARC se entrelaza con tales movilizaciones. ${ }^{25}$ Años después vuelven a tener remarcada presencia, esta vez como abanderadas de la protección frente a los desmanes guerrilleros; no en vano el paramilitarismo toma el nombre de autodefensas unidas de Colombia. ${ }^{26}$ Frente a esta sinuosa trayectoria el Estado se comporta de manera ambivalente. Hasta la década de 1980 les dio carta de ciudadanía mediante un reconocimiento legal que sirvió de paraguas al crecimiento paramilitar; pero una vez que éste creció y adquirió una impensada autonomía, se modificó la ley que las amparaba convirtiéndolas en organizaciones ilegales. ${ }^{27}$ El término de autodefensa es pues problemático y no es empleado en las ciudades. Allí son variados los nombres que describen la misma experiencia de autoprotección. El más reconocido es, sin duda, el proyecto antioqueño de las milicias populares, una organización que llegó a pactos con el gobierno y la posterior constitución de empresas legales de vigilancia y control local. ${ }^{28}$ En las ciudades de nuestro interés adopta nominativos como encapuchados, cuchos, comités de vigilan-

cia. En estas condiciones el término de defensa urbana resulta conveniente: apuntala la acción de unos vecinos que se arman dispuestos a proteger lo que consideran suyo. Se diferencian de las policías comunitarias en que cortan su dependencia con los cuerpos formales de seguridad - aunque entre sus filas militen agentes del Estado, activos o retirados-, medida necesaria porque su ánimo es aplicar justicia por cuenta propia.

La defensa urbana es, entonces, un destacamento ya no de simple vigilancia sino, además, de impartición de justicia. Se arman y se organizan de manera independiente y salen a patrullar el barrio. Los hay de dos clases, uno formado por los mismos vecinos y otro armado con agentes

\footnotetext{
${ }^{24}$ Un trabajo sobre diversas facciones armadas durante la violencia de mediados de siglo, entre otras, las autodefensas, véase en Ortiz (1985). 25 Pizarro (1996).

26 Sobre la primera formación de las autodefensas actuales en el Magdalena Medio véase Medina (1990). Una historia reciente puede consultarse en Romero (2000).

${ }^{27}$ Hasta el día de hoy la ley no ha sufrido modificación legal, pero el tema de su renovada legitimación ha estado siempre presente, más con el proyecto de ciudadanos informantes.

28 Téllez (1995).
}

externos. En el primero, los vecinos pueden participar como ejecutores directos de los ajusticiamientos: "Hay veces que hacen autolimpiezas los mismos del barrio, los cuchos salen con sus máscaras a tumbar hasta los del frente de la casa." No obstante, su forma más extendida es el hostigamiento a los parches mediante la golpiza severa. Sus armas usuales son objetos contundentes como palos o tubos, aunque algunos portan pistolas para protegerse en un medio donde las armas letales circulan con facilidad. Aparecen de manera esporádica, en las coyunturas de expoliación pandillera. A veces, las menos frecuentes, la justicia vecinal deriva en organizaciones estables empeñadas en "sanear" el barrio. La más memorable de Bogotá, los encapuchados, se convirtió en un grupo de vigilancia y castigo dedicada a propinar duras muendas a los jóvenes sorprendidos en caminadas nocturnas. ${ }^{29}$ Sus rondas se cumplieron hasta que su violencia indiscriminada les quitó el apoyo de la gente, forzando su disolución: "Entre los encapuchados habían unos policías además de la gente del barrio. Esos caían hasta los sanos, apenas por ir fumando o borrachos." 30 Caminaban el vecindario de las diez de la noche en adelante. Constituidos por algo así como sesenta miembros se repartían en grupos asignados a distintos puntos del barrio. Conocedores del vecindario y sus intrincados recovecos arrinconaron a los parceros, hasta que el embelezo de la justicia los llevó a cometer toda clase de abusos.

El segundo tipo de defensa urbana, en forma distinta, se organiza como un servicio de seguridad privado conformado por personas extrañas que cobran una paga por su trabajo. El más famoso es el de los conocidos Mesas en Barranquilla, una forma hoy extendida entre los barrios populares de la ciudad costeña. El rasgo que los caracteriza es una desembozada determinación de matar, cumplida sin el menor miramiento. Armados con pistolas y revólveres, están siempre firmes en la resolución de ultimar a todo aquel sorprendido en la más leve infracción.

\footnotetext{
${ }^{29}$ En Barranquilla también hubo encapuchados hacia finales de los años 1980 y principios de los 1990. En Neiva, igual, proliferaron durante una época.

${ }^{30}$ Richard, Bogotá, p. 35; Efraín, Bogotá, p. 12. Tumbar es matar; sano es un joven no metido en nada.
} 
Aplican la misma norma del terror pandillero, de ahí que los parceros les guardan respeto: "No nos gusta boletearnos por ahí porque al que vean los Mesa robando le van dando candela de una." Por supuesto, ante tal decisión violenta no faltan enfrentamientos cruzados: "Varias veces nos hemos enfrentado con ellos, uno de nosotros se bajó a uno. Dejaron de meterse por allá." Nacieron en el barrio La Chinita, ubicado en un sector popular de otra comuna de la ciudad, en la casa de una familia de apellido Mesa decidida a "limpiar" el barrio de maleantes y pandilleros. Su ferocidad resultó proverbial, en el sector donde operaron amainó de manera considerable la criminalidad, permitiendo que la acción inicial se prolongara luego en el cobro de un impuesto a los vecinos con la contraprestación de una vigilancia permanente del sector. En la zona de nuestro interés la modalidad de vigilantes privados con total determinación de usar sus armas aparece, al comienzo, bajo la forma de acompañantes de los transportes privados como colectivos y camiones de empresas: "Los Mesa escoltan los buses, el carro de la leche, la coca cola, la postobón, al de la carne, al del pan." Los atracos a estos vehículos, antes permanentes, casi desaparecieron. Pasado algún tiempo el servicio de vigilancia se extendió a las calles del barrio, al principio sólo durante las noches y luego a lo largo del día. Hoy casi todos los barrios del sur cuentan con sus Mesa, personajes que se desplazan todo el día en una moto pasando a recibir su pago el día sábado. Un pastor evangélico lo cuenta: "Anteriormente no podía entrar un policía. Los Mesas son un grupo de limpieza que patrullan a toda hora. Todas las tiendas del sur les pagan 2000 pesos semanales. Si alguien se quiere afiliar simplemente habla con ellos y da una cuota. En la actualidad es difícil escuchar que atracaron una tienda." 31

Su función es no sólo preventiva —una imagen legitimada a costa de un sinnúmero de muertes—, sino también investigativa: "Impiden los atracos pero si los hacen investigan quiénes lo hicieron y si los pillan los matan." Su justicia arbitraria y sanguinaria les ha creado toda

${ }^{31}$ Mechete, Barranquilla, p. 10 y 11; Faustino, Barranquilla, p. 5. Boletearse es hacerse notorio; dar candela es disparar.

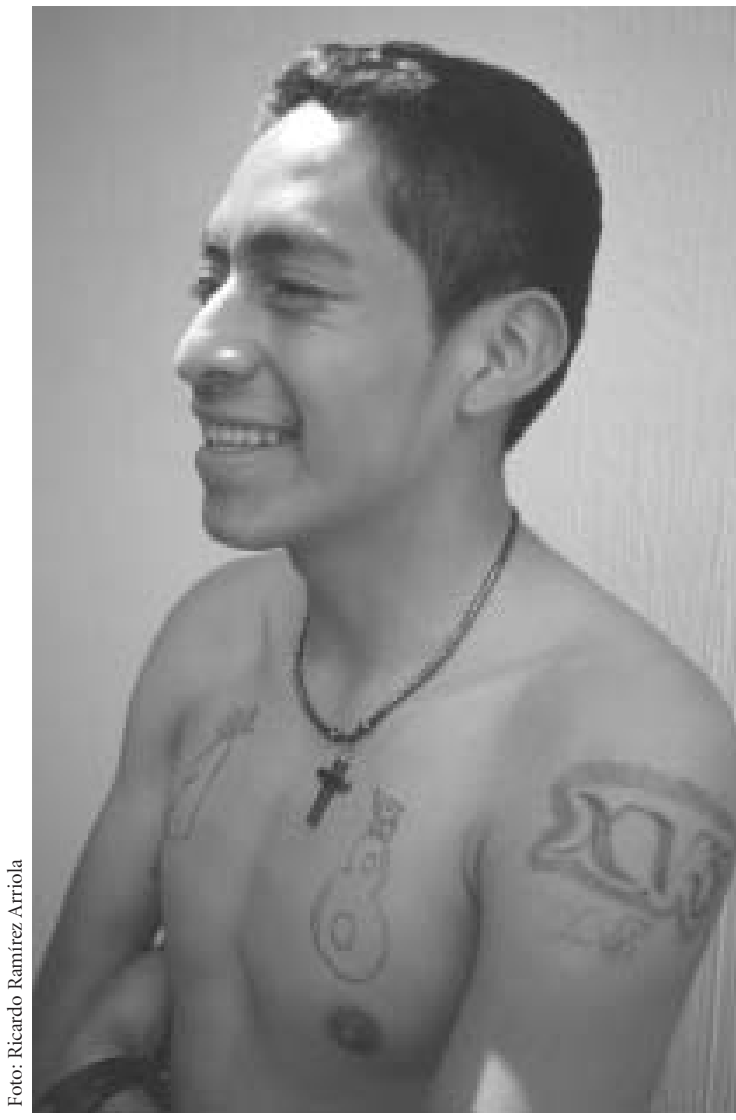

"La primera vez fue horrible. Luego como que te acostumbrás a verlo, a sentirlo, a hacerlo. Tu esquema se va formando así. Tenía 14 años."

clase de animadversiones. Como suele suceder en estas justicias privadas abundan las anécdotas de inocentes caídos bajo su ley implacable: "Quien cogen mal puesto lo matan. Con ellos se ha reducido la delincuencia pero han matado pelados que no son rateros. Es una injusticia porque antes de matar se debe practicar un proceso, ellos toman la justicia por las manos." Al mirar de algunos son un grupo de mercenarios sin ninguna conciencia de la vida local: "Para mí es una cuadrilla de extorsionistas porque cuidan los tenderos que les pagan pero no la casa del lado, es una especie de paramilitarismo." Una vez sentenciado alguien, su persecución no tiene reparos: "Los Mesa nunca me lograron agarrar. Me perseguían y me les escondía. Cuando supieron dónde vivía no salían del pedazo buscándome, no podía salir de la casa." El resultado 


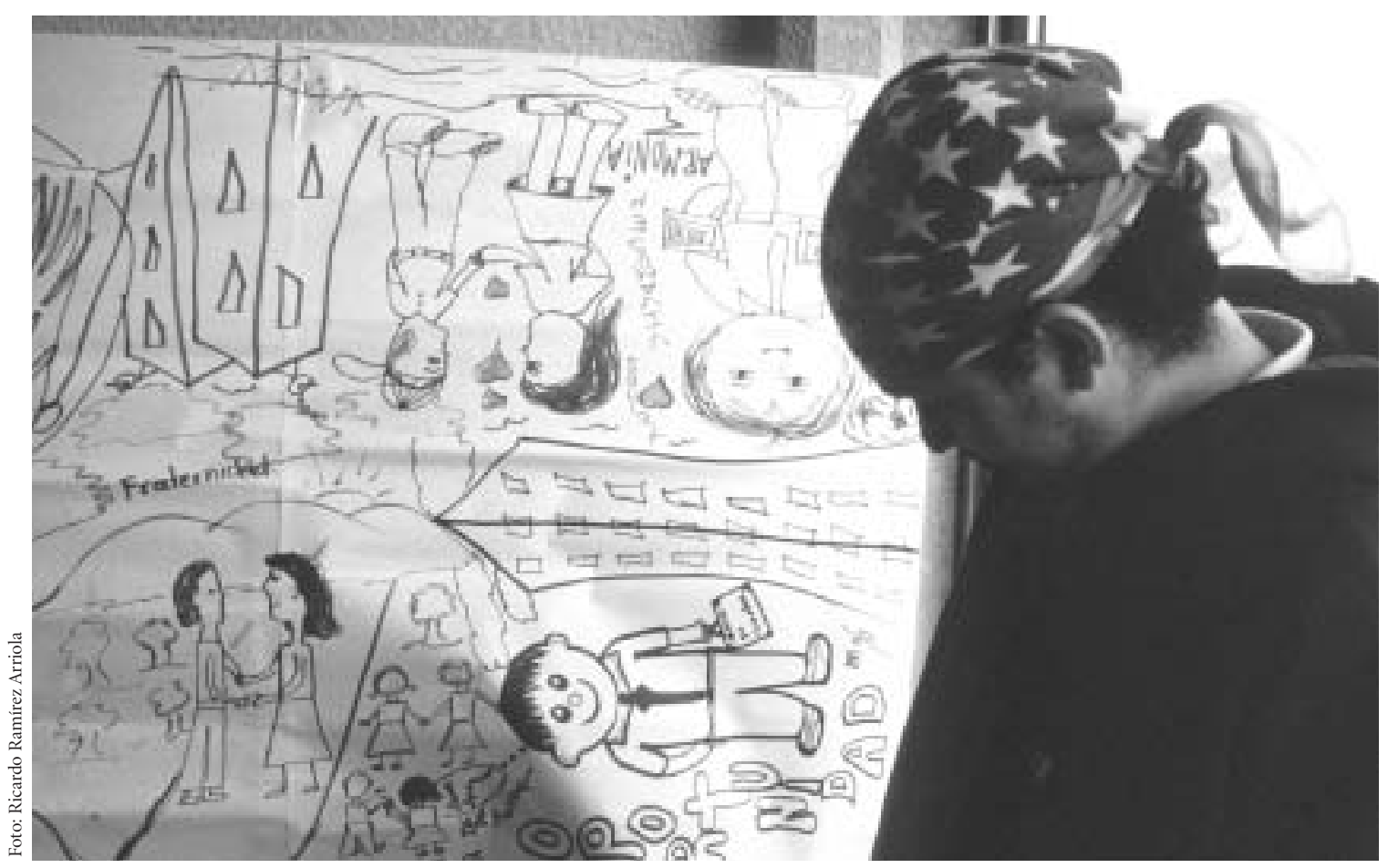

"Yo era como un vagabundo por las calles, cegado por la oscuridad de mi corazón, por la oscuridad de mi hogar donde nunca me dieron luz por donde empezar a vivir."

de un actor con tanta contundencia ha venido a ser el repliegue de los pandillos, forzándolos a desplazarse en sus actividades: "Ya no nos metemos con nadie, nos vamos a atracar y pelear lejos." Y gran paradoja, el mercadeo de la muerte ha llevado a que muchos parceros terminen enlistados entre los Mesa atraídos por el salario: "Muchos han dejado de trabajar pa' irse con los Mesa porque les pagan más." 32

El conflicto entre los pandilleros y los vecinos adquiere proporciones dramáticas. Los moradores del barrio reaccionan con una variedad de estrategias, unas individuales y otras colectivas, desperdigadas entre la presión a las autoridades, las vigilancias comunitarias y las defensas en abierto pugilato con los parceros. En las tres ciudades, una y otra modalidad de respuesta vecinal han

${ }^{32}$ Faustino, p. 5; Pendenciero, pp. 12 y 14; Anónimo por razones de seguridad; Mechete, p. 11; Furtivo, p. 12. Todos son de Barranquilla. estado presente. Sólo en contadas ocasiones el proceso sigue la dirección lineal de la narración anterior. Acontece más bien que las distintas respuestas defensivas del vecindario se combinan en el tiempo y la distancia. Mientras que en Barranquilla hoy dominan los Mesa, en Bogotá se han extendido las policías cívicas, claro, gracias a las campañas de exterminio que le preceden o a la siempre acechante posibilidad de nuevos asesinatos. El espectro de la muerte está presente, aparece sin titubeos en las defensas contratadas como los Mesa, pero su expresión más cruda y desgarradora adquiere forma en las operaciones de limpieza.

\section{OPERACIONES DE LIMPIEZA}

La tramitación sangrienta del conflicto local con la pandilla adquiere expresión, en su forma más brutal, en las operaciones de limpieza, ese horripilante nombre endo- 
sado al sistemático asesinato de cualquier minoría reputada de "indeseable". Los jóvenes de las barriadas populares serán un blanco predilecto de la matanza: en nombre de la eliminación de los parches se entronizarán una serie de prácticas encaminadas a eliminarlos.

Desde finales de la década de 1970 comenzó a circular la noticia de asesinatos múltiples en las calles de las ciudades. La práctica de masacres horrendas, en las que se descuartizaba a grupos de gente, es un viejo y conocido procedimiento de "lucha" en Colombia; las matanzas de mediados de siglo con su desbordada sevicia lo atestiguan. ${ }^{33}$ En tiempos cercanos la modalidad ha hallado más de un confeso seguidor, en particular en el delirio paramilitar cínicamente justificado en el hábito de masacrar poblaciones completas bajo el argumento de eliminar las bases sociales de sus enemigos. Así las cosas, las masacres iniciadas a finales de la década de 1970 se inscriben en una modalidad de probada trayectoria; sus ejecutorias, empero, participan de una doble condición que les proporciona enorme singularidad. Por una parte, tienen asiento en la ciudad, su escenario es la calle y no la vereda rural; por otra, sus víctimas están investidas de nueva identidad, se trata de homosexuales, trabajadoras sexuales, habitantes de la calle, ladrones. La enseña política se refunde, reemplazada por la consigna puritana de quienes se sienten llamados a restituir el orden perdido decretando la muerte de aquellos juzgados "indeseables". Como acontece siempre con estos agentes privados, reivindicados en el papel mesiánico de “ángeles guardianes", estalla en pedazos la frontera entre sujetos diferentes y seres peligrosos, lo uno reducido y aplastado en lo otro. Una vez comenzada la práctica en una atribulada capital paisa, y para desgracia de la maltrecha identidad ética colombiana, el remedo de la crueldad generalizó estas masacres en las ciudades del país. ${ }^{34}$ Breve tiempo después los pandilleros entraron a formar parte del desfile luctuoso, una vez incorporados se convirtieron en el objetivo más destacado.

\footnotetext{
33 Sobre las masacres de mediados del siglo XX véase Uribe (1990); sobre las de tiempos recientes, Uribe y Rojas (1998).

${ }^{34} \mathrm{La}$ ciudad donde primero se escuchó de los escuadrones de la muerte fue Pereira. Véase Rojas (1996).
}

La limpia, así se le conoce coloquialmente en los barrios. Su sólo nombre espeluzna. Declara sin ambages la intención de quien se presume dueño del prurito de señalar lo impuro, de aislarlo y neutralizarlo; un poder por nadie conferido, pero asumido hasta el asesinato sin fórmula de juicio. La limpieza pone su dedo acusatorio sobre aquel que estima fuera del curso de la vida y, sin más, lo arrincona y desaparece. Es la parodia de la cacería urbana, resonancia de los más brutales exterminios. El "limpiador" es un criado dócil. Cumple su tarea animado por el sueño inútil de una ciudad liberada de disidencias, cuando en realidad no es sino el lacayo de la extravagancia clasista obsesionada con suprimir la pobreza eliminando lo "estorboso y feo". Chata y oscura extravagancia clasista: la totalidad de sus víctimas son miembros de los sectores populares, jamás se ha emprendido nada parecido contra ladrones de cuello blanco, multimillonarios desfalcadores de las arcas estatales. La gente sabe de qué se trata: "Decían que la limpieza era pa' acabar con la escoria de la sociedad." ${ }^{35}$ La tal "terapéutica" pone bien en claro el absurdo de la sociedad contemporánea frente a su conflicto: como lo evidencian los pandilleros, los dispositivos culturales provocan exclusiones frente a las que desaparece cualquier alternativa distinta a la del asesinato y la muerte.

Sin duda, la limpieza mueve terrores profundos. Sus formas de hostigamiento, que invitan al sepelio de los futuros sentenciados mediante carteles colgados en los postes de las calles, así como sus fulminantes formas de operación, le granjearon el lugar de enemigo feroz de las pandillas: "Duró un tiempo que uno veía los avisos que invitaban al propio entierro, ‘ ¿cómo así, no me he muerto y están invitando al sepelio mío?’” En Bogotá, su incursión es la responsable del cambio operado en las pandillas hacia mediados de la década de 1980, barriendo de tajo los antiguos parches con sus ritos y emblemas. Hoy los parceros no se pueden dejar identificar con claridad. Aunque su presencia local pasa por el exceso y la exposición pública, los tatuajes, los nombres y símbolos distintivos, las grandes agrupaciones y el amplio poder territorial

\footnotetext{
${ }^{35}$ Robin, Bogotá, p. 18.
} 
de las pandillas anteriores desaparecieron. No hacerlo implica caer en la necedad de exponerse a la limpia: "Las pandillas de antes las tumbó la sociedad cuando decidieron hacer sus famosas limpiezas sociales, matar jóvenes por estar en un grupo." Como se cuenta también en Barranquilla, "conocí un muchacho que se ponía una plancha caliente para borrarse el tatuaje porque lo andaba buscando la limpieza." 36

En las tres ciudades las operaciones tienen presencia. Lo acabamos de oír en Barranquilla y Bogotá, igual se da en Neiva. "Me da miedo venirme de madrugada porque está dando mucho la Mano Negra, desapareciendo gente." Los datos poco aclaran, se dispone tan sólo de la referencia de $42 \%$ de pandillos asesinados por la limpieza en Neiva. ${ }^{37}$ A pesar de sus actuaciones, desde hace algo más de dos décadas, sus acciones permanecen recubiertas de un halo de misterio y un manto de impunidad. Su "invisibilidad" las convierte en suceso del orden de lo innombrable: los textos sobre la inseguridad y las acciones para contenerla ni siquiera las mencionan, haciendo caso omiso de una de sus estrategias preferidas, la masacre. ${ }^{38}$ tencia de 26 homicidios colectivos con un saldo de 129 víctimas; en la localidad de San Cristóbal en particular, zona de nuestra indagación en la capital, un estudio especializado menciona nada más tres masacres, mientras Medicina Legal habla de cinco. ${ }^{39}$ Los datos resultan poco creíbles, reducidos en comparación con las historias desperdigadas entre los barrios. Los recuerdos, por cientos, los desmentirían. Es cierto que la memoria, tan frágil e interesada, está plagada de trampas; mas las anécdotas pululan con tal fuerza que resultaría necio no otorgarles una escucha: "Mataron como unos doce manes, otra vez mataron como a cinco, quedaron botados a las dos de la

\footnotetext{
36 Robin, Bogotá, pp. 38 y 18; Faustino, Barranquilla, p. 2.

${ }^{37}$ No se pudo establecer un dato sistemático en Bogotá y Barranquilla. 38 Observatorio de Cultura Urbana (1997). Lo mismo sucede en la prensa, donde las operaciones casi ni aparecen. Al respecto véase Pérez y Mejía (1996: 152). La resistencia de la policía de la localidad de Suba a nombrar el hecho aparece en García (1998).

${ }^{39}$ En los registros de la Policía Nacional los datos sobre masacres aparecen discriminados apenas desde 1990. El estudio especializado de Rojas (1996: 28) habla a partir de una exploración de la prensa. Segovia (1994) transcribe varios artículos periodísticos al respecto.
}

mañana”, se habla en Bogotá. "El año pasado resultaron hartos muertos. Hubo como cinco, los dejaban en la calle o aparecían en el hueco", se cuenta en Neiva. ${ }^{40}$ Entretanto, en Barranquilla venían disminuyendo sin desaparecer del todo; la sostenida presencia de los Mesa las había vuelto redundantes. ${ }^{41}$

Pese a que narraciones de igual tenor se escuchan en las tres ciudades, en ninguna se conoce rostro alguno de sus ejecutores. Se cuenta de la participación de estos y de los otros, en medio de historias desprovistas de pruebas contundentes. Con todo, en medio de la incertidumbre, es posible detectar la participación de tres tipos de actores: vecinos del barrio, organismos de seguridad del Estado, sicarios contratados para el efecto — de quienes no alcanzamos a ocuparnos en este artículo- - . En la práctica, unos y otros se mezclan en el tiempo y las estrategias. La participación de los vecinos, en primer lugar, se produce de varias maneras. Lo hacen como autores intelectuales en complicidad con los escuadrones de seguridad del Estado. En este caso su misión consiste en apoyar la elaboración de listas mediante la entrega de información sobre los parches y sus miembros: "En la limpieza participa la gente del barrio, tiene que hacerlo porque si no los del F2 cómo van a saber a quiénes hay que tumbar", señala uno. "La limpieza son la misma comunidad, se organizan en una casa para decidir que acaben éste y éste 'porque nos están dañando la cuadra'”, ratifica otra. Ahí no se agota su papel, funcionan también como autores intelectuales contratando personas dedicadas al oficio, conectadas en sitios especiales de la ciudad que ofrecen el "servicio": "La comunidad llama gente. Saben qué personas lo hacen y pagan para que maten", asevera el primero. "La comunidad va al centro, cogen a un man propio y le dan tanto por tantos muchachos", declara el segundo. La pregunta de quiénes son las personas de la comunidad no tiene respuestas inequívocas, con mayor razón

\footnotetext{
40 Jaime, Bogotá, p. 12; Eleonora, Neiva, p. 11.

${ }^{41}$ La afirmación vale para el momento de finalización de nuestro trabajo de campo, a comienzos de 2003. La formidable incursión del paramilitarismo en las ciudades, justo de ese momento en adelante, arroja todos los indicios de la reaparición y auge de las operaciones de limpieza.
} 


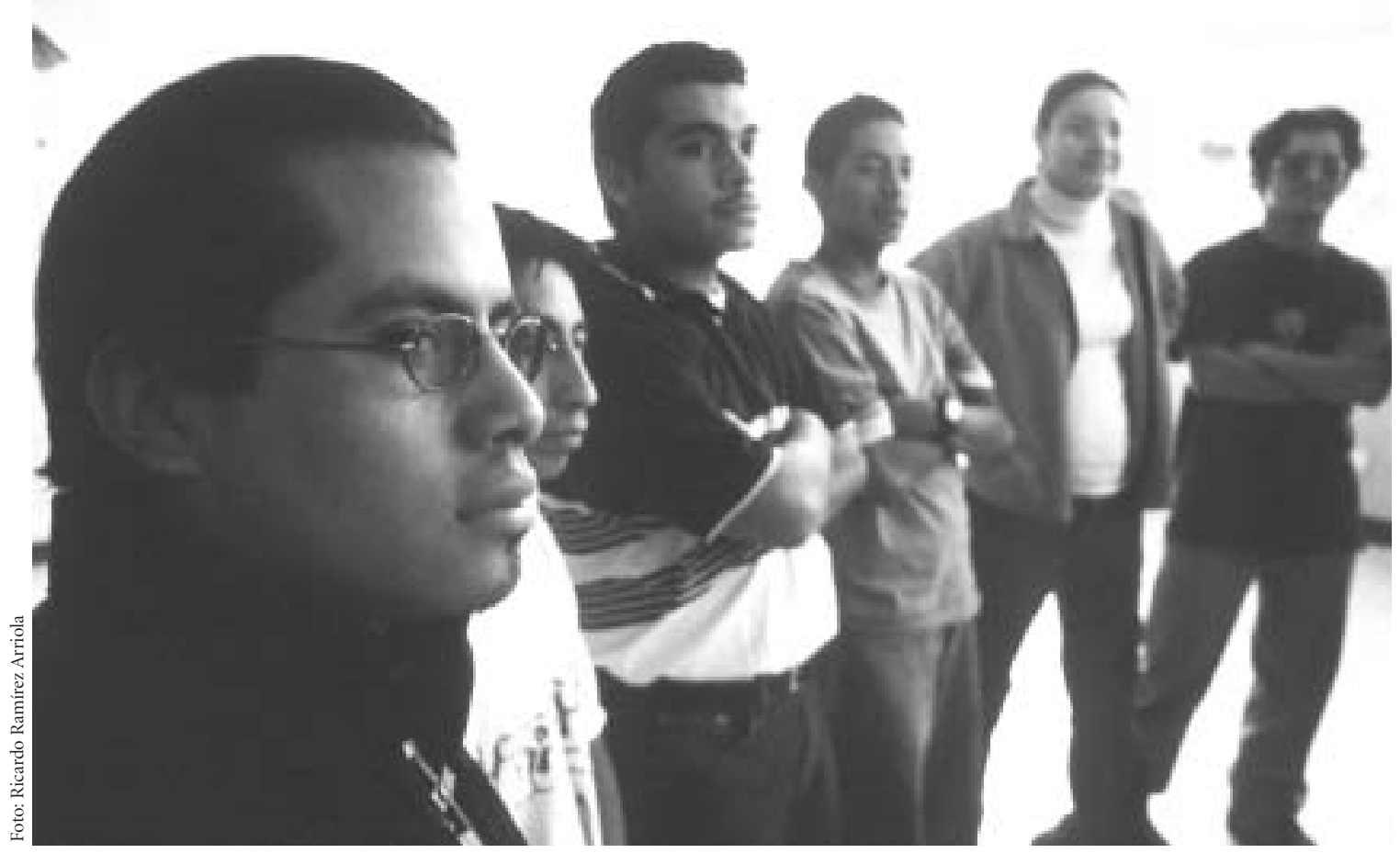

"En febrero mataron a Marco Vinicio Rivas, un compañero en este proyecto. Acababa de salir de la cárcel y tenía un montón de ilusiones, como poner una casa para jóvenes drogadictos.”

en medio de un conflicto de agigantadas proporciones. Sin embargo, casi siempre se señalan los miembros de las juntas de acción comunal. A veces actúan a título propio asumiendo la vocería del vecindario, otras lo hacen en arreglo con vecinos, casi siempre comerciantes con el interés de extirpar los parches que ahuyentan sus clientelas y, claro, con el dinero para sufragar el gasto: "El man de la acción comunal es el que más habla, el más sapo como quien dice", cuentan en Bogotá. En Neiva se comenta lo mismo: "La junta de acción comunal del barrio son unos sapos, no son sino gonorreas", dice uno. "Se rumora que son los mismos del barrio, los presidentes que contratan matones pa' que limpien", certifica otra. ${ }^{42}$

El segundo protagonista de la limpieza son los organismos de seguridad estatales. Su decisivo papel es denun-

42 Richard, p. 35; Gladys, p. 12; Hernando, p. 6; Efraín, p. 28; Caballo, Neiva, p. 14; Eleonora, Neiva, p. 11. ciado sin titubeos, pese a la inexistencia de condenados por ello: "La limpieza la conforman rayas, fuerzas especiales, policías especiales, hasta infiltrados en las pandillas." Resulta imposible establecer los vínculos entre unos destacamentos y otros. La policía cumple su misión, sea en la información, sea en la ejecución. Se habla de organismos especializados en la tarea, miembros de distintos cuerpos agrupados para el efecto. Se dice en Bogotá: "Hasta donde se tuvo entendido la limpieza era el DAS, los llamados Gatos, el F2 y la misma policía.” También en Barranquilla: "Dicen que la limpieza eran policías disfrazados con otros de la defensa civil." Lo mismo en Neiva: "Los que hacen eso son la Sijin. Dicen que la Mano Negra viene de Medellín, mentiras, son ellos, sino que se cambian, se disfrazan y salen tarde la noche a matar." Los indicios abundan, las pruebas escasean. Las fuentes más fiables provienen tanto de vecinos pertenecientes a los cuerpos de seguridad como de parceros llamados a participar en el trabajito. Los primeros avisan la proximidad de las limpiezas, "gente 


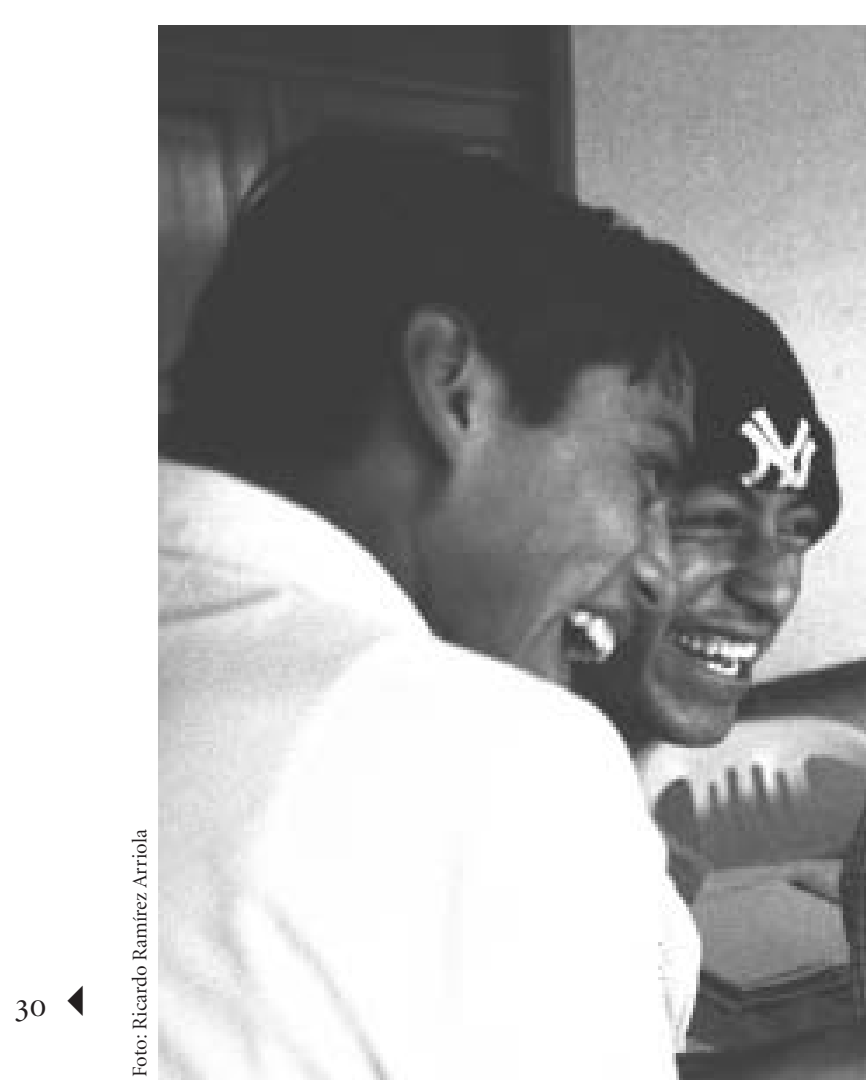

"Pasé dos años durmiendo en el quiosco de un parque. Allí dormía sólo con un suéter. Amanecía llorando cuando llovía."

dentro del DAS informaban cuando iban a salir a hacer limpieza, porque acá hay gente que vive en este ambiente y le duele que les dañen donde ellos viven". Los pandillos enrolados, por su parte, hablan de la identidad de sus contratantes: "Trabajaba con la misma policía en limpieza de otros barrios. Le decían 'hay un pelado tremendo, anda con armas matando'. Venía y con otros dos muchachos de la banda iban y lo mataban." ${ }^{43} \mathrm{~A}$ pesar de la contundencia de las matanzas y las evidencias de sus ejecutores la impunidad se impone. Hasta donde se tiene noticia no se ha producido ni una sola sanción a los responsables de las muchas incursiones de estas fuerzas:

\footnotetext{
${ }^{43}$ Yeison, Bogotá, p. 77; Robin, Bogotá, p. 24, Faustino, Barranquilla, p. 2; Parcerito, Neiva, p. 12; Pendenciero, Barranquilla, p. 13. Raya es detective estatal; las siglas son cuerpos de seguridad del Estado.
}

con claridad, el silencio cómplice de las autoridades revela su participación interesada.

Las operaciones hacen acto de presencia cada determinado tiempo, con asaltos irregulares y sorpresivos: "La limpieza son por épocas, llega a ratos, se pillan que hay hartos chinos, los bajan y se abren." Su carácter inesperado es constante de ciudad a ciudad: "Hay temporadas que se escucha que va a hacer limpieza." A veces la policía las anuncia, en parte como forma de prevención de sus potenciales víctimas, en parte con la pretensión de aplacar los parches: "Cuando los policías hacen raqueta dicen 'estén en la juega, no los queremos ver por acá porque vamos a hacer limpieza." El ritmo de sus incursiones no sigue un patrón fijo sino que guarda relación con la temperatura de los parches, concentrando su acción en periodos cortos pero fulminantes y dirigida a las pandillas más ajizosas: "El barrio siempre vive cosas pero hay temporadas más fuertes, en que no se puede llegar después de las ocho porque se siente el ambiente de las pandillas." Tal parece ser la conexión esencial, aunque las épocas de finales de año suelen ser el momento preferido: "Eso ya estaba fijo, todos los diciembres la limpieza iba y armaban la masacre."44 Incluso las autolimpiezas, como llamó un muchacho las defensas conformadas por vecinos, actúan con la misma lógica de reacción al ascenso de la violencia pandillera, con la excepción de las defensas permanentes dedicadas a vigilar noche tras noche.

Las listas negras encuentran sus fuentes de información en vecinos y registros policiales, aunque también se mencionan visitas de miembros de organismos especializados vestidos de civil, quienes hacen en el terreno una labor detectivesca para la ubicación de los parches y sus mañas: "La limpieza son tombos de particular que llegan y fichan a los pelados." Se mencionan soplones infiltrados en las pandillas. Los anuncios de las limpiezas, presentes en las tres ciudades, unas veces contienen nombres - líneas arriba se leyó a un muchacho bogotano aterrado ante el adelanto en vida de su funeral- y otras simplemente se limitan a la mención de la acción que se

\footnotetext{
${ }^{44}$ Gertrudis, Neiva, pp. 22 y 14; Tico, Bogotá, p. 69; Humberto, Bogotá, p. 35; John, Bogotá, p. 41.
} 
aproxima: "En ningún momento dicen usted y usted, dicen solamente cuídense que van a hacer limpieza", narra alguna; "han puesto anuncios que van a hacer limpieza pero no nombran a los muchachos" 45

Existen diversas formas de ejecución. En una, la más mortal, caen unos sujetos en un vehículo rociando a los jóvenes parados en la esquina. En Bogotá se le puso el apelativo de gato a los vehículos empleados en esta ruin faena: "Tarde de noche veíamos carros por ahí, los dichosos gatos los veía uno rondando." En Neiva se emplea el procedimiento: "Allá ven un carro y arrancan a correr porque pasan en camioneta y disparan." Igual se emplean motos, en particular en Neiva, ciudad donde buena parte de la población se desplaza en ellas: "Se escuchaba las motos cuando pasaban y los disparos, pero nadie se asomaba de miedo." El disparo rápido no discrimina entre culpables e inocentes, como se repite hasta el cansancio: "Están fichados los que tienen que matar, pero si uno está ahí pasan disparando no importa quién maten." En todas partes abundan las historias de muchachos sanos arrastrados en la desfortuna de estas prácticas: "Llegaron dos camionetas. Más nos demoramos en verlas cuando se bajaron un poco de manes de paño, sacan los tubos y nos enciendan a plomo, a mansalva al que cayera." La rociada no es el único procedimiento, asimismo se estila la ejecución selectiva buscando las víctimas, lista en mano, apostados en lugares estratégicos del barrio, interrogando a cuanto muchacho se atraviese en el camino: "Estaban en la entrada de Guacamayas, preguntan a los chinos cómo se llaman y que muestre los papeles, si es el que buscan lo bajan de una”, es un caso en Bogotá. "Llegó un carro, llamó un parcero, disparó y lo dejó ahí; al otro día otro parcero y así", es otro en Neiva. Igual sucede que la identificación selectiva no concluye en el asesinato instantáneo, se prolonga en el paseo fatal por las afueras de la ciudad: "A veces se los llevan y la montan de alegría, los chuzan, les pegan, los pelan, les dan pata, los torturan, los matan. Se los llevan para otra parte y los dejan por allá." Sólo un milagro de la vida hace posible

45 Tico, Bogotá, p. 69; Gertrudis, Neiva, p. 14; Eleonora, Neiva, p. 11. Tombo es policía. la posterior narración de lo que acontece en un viaje de aquéllos: "Nos llevaron pa'l botadero de doña Juana. Estaban encapuchados, sacaron los tubos y dijeron que iban a contar hasta tres. Corrí y empezó una balacera ni la berraca hasta que me tiré en un montón de basura. Me buscaron pero no me encontraron, yo ahí paralizado hasta las seis de la mañana. Nunca había tenido tanto miedo." Sólo en contadas ocasiones los sentenciados se le fugan a la muerte, la mayoría de las veces los cuerpos inertes se convierten en testimonios elocuentes del terror: "A veces aparecen los muertos tirados en el paradero de las Columnas", un paraje de amplia circulación y populosa concurrencia en el corazón de un barrio en Bogotá. ${ }^{46}$

El rasgo característico de la limpieza es su anonimato. La capucha se encarga de cubrir la identidad, acompañada, entre las autodefensas, de ruana y guantes a fin de encubrir el cuerpo del victimario. Sin embargo, su principal enmascaramiento funciona con el asalto sorpresivo que, entre la velocidad, el pánico y la amenaza, cubre la cara de sus ejecutores. En múltiples oportunidades la limpieza quiebra la continuidad del parche, "decidí retirarme cuando empecé a ver caer compañeros, los mataban las limpiezas". En otros casos lo debilita mediante el emplazamiento de uno de sus momentos predilectos, el de la noche: "Desde ahí no volví a pasármela hasta tarde por ahí. Eso fue lo único que me hizo reflexionar." No obstante, en el otro extremo, genera una de las tantas espirales violentas que no dejan de sacudir a Colombia: "Los parches se integraron y cuando entraban a hacer limpieza los atacaban. Esperaban el vehículo por tal lado, le hacían una emboscada para hacerles sentir lo mismo que ellos sentían." La presencia de un enemigo común puede hacer ceder rivalidades que de otro modo serían insuperables: "Si a un parche llegaba la limpieza el otro buscaba ayudarlos, así no se quisieran como parche, siempre la unión porque somos del Suroriente. Cuando le hacían daño a un grupo todos se ponían de acuerdo para hacer daño también." De buen grado, las correrías de

${ }^{46}$ Robin, Bogotá, p. 32; Mundano, Neiva, p. 74; Eleonora, Neiva, p. 11; Niche, Bogotá, p. 12; Tico, Bogotá, p. 70; Gertrudis, Neiva, p. 16; Caballo, Neiva, p. 13; Niche, Bogotá, p. 33; John, Bogotá, p. 38. Tubo es arma de fuego. 
las limpiezas derivan en una apuesta donde se juega la astucia y se activa la anhelada adrenalina que tanto excita la actividad pandillera: "Si uno les da la pata lo tumban, siempre y cuando lo encuentren en un lado solo para que lo puedan echar al carro sin que nadie se de cuenta, si los ve alguna persona se azaran." 47

Se trata pues de una muerte sin rostro, hundida en el turbio argumento de acabar la escoria de la sociedad. A lo más, los escuadrones de la muerte dejan huellas de su identidad mediante la colocación de un cartel sobre el cuerpo inerte de la víctima, consignando el nombre de la organización o la frase síntesis de su "campaña". Ahí reside la diferencia entre la operación de limpieza y el escuadrón de la muerte, en la circulación pública del acto homicida. Sus procedimientos son los mismos, aniquilan sin compasión envueltos en el misterio con el propósito de propalar el terror y el miedo; pero mientras la operación no reivindica identidad ninguna, el escuadrón, a través de las señas con que marca la víctima, declara la presencia de una voluntad organizada dispuesta a abanderar una cruzada moral. De alguna manera los escua- ban una mano en el lado izquierdo de la cara. Sembraban el terror." 48 En todo caso hoy el escuadrón es poco corriente, lo fue tiempo atrás, abriendo paso a la forma típica de la operación de limpieza. El paso del escuadrón a la operación en los barrios populares habla de una mutación acorde con la creciente degradación de la guerra en Colombia: la muerte se extiende y generaliza, sin que aparezcan autores reconocidos asumiendo su responsabilidad. Simplemente se perpetra, gesticula desde la contundencia del asesinato y la mutilación, pero carece de toda habla que la conecte a las tensiones de la cultura y la tramitación argumentada del conflicto.

\section{A MODO DE CIERRE}

La pandilla es una forma de habitar la ciudad. No desde cualquier lugar, sino desde la ciudad puesta en los límites, entre la pobreza y la marginación. La pandilla brota de la miseria, no lo hace en ninguna otra condición social. Aunque no faltan los grupos calientes entre sectores medios y altos. "Hay bandas de chinos gomelitos... Les gusta tomar al piso y meter perica... sacan los fierros y se van a hacer sus vueltas", comenta alguno en Neiva. ${ }^{49}$ En Bogotá también, de vez en cuando, suena la noticia de muchachos de estrato alto comprometidos en la mezcla de consumos y actividades delictivas. El caso más sonado fue el de una banda barranquillera conformada por muchachos adinerados, dedicados al pillaje, hasta que las autoridades la desmantelaron. De seguro habrán más ejemplos de naturaleza similar; con todo, no pasan de ser experiencias aisladas, nada parecido al fenómeno social que aflora en la miríada de pelados azotando las zonas populares según revelan los datos de su difusión.

Los parceros conectan entonces con la desigualdad y la pobreza, un tema al que es preciso retornar más allá de la visión que le reduce a mero problema técnico, a simple asunto de inversión y gestión económica. Como nadie más lo hace, la pandilla denuncia la exclusión y señala

\footnotetext{
48 Sonrisa, Neiva, p. 12; Bernardo, Bogotá, p. 35.
}

${ }^{47}$ Las dos primeras frases son de Robin, Bogotá, p. 24; Parcerito, Neiva, p. 12.

\footnotetext{
${ }^{49}$ Parcerito, Neiva, p.15. Fierro es arma.
} 


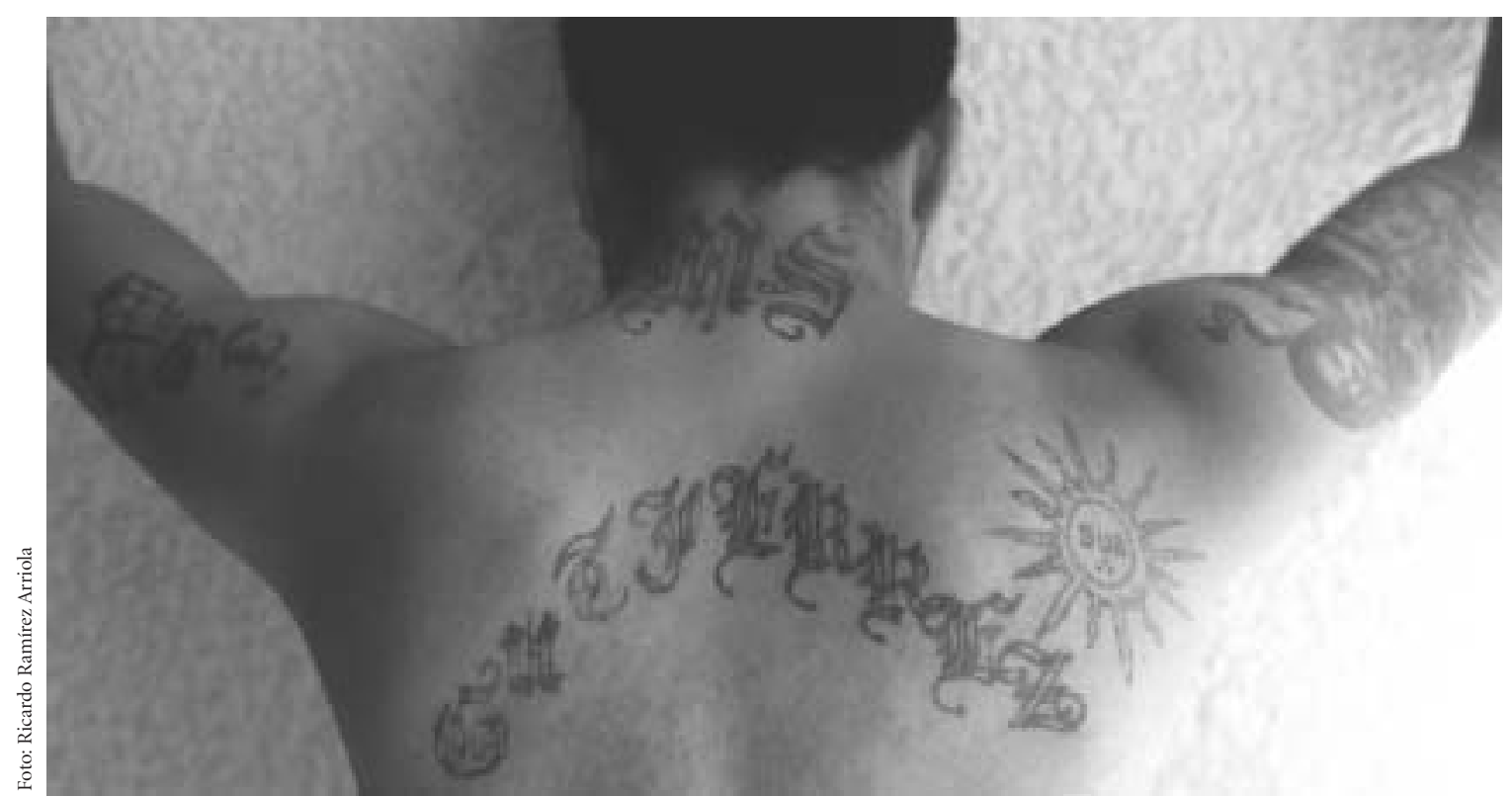

"La experiencia en la cárcel es dura. Tienes que hacerte respetar. Siempre va a haber alguien que te va a querer ganar. Es donde tienes que decirle no, aquí no te pasás de lanza."

la marginación: su existencia más allá de los arreglos de la vida colectiva, protagonizada por muchachos de corta edad, ocupados en nada distinto a la esquina, ¿no lanza el más devastador interrogante sobre el proyecto cultural que encierra la ciudad? La denuncia pandillera se hace con desparpajo, como una suerte de alarido desenfadado, desprovista de discurso alguno sobre su subversión extrema. Los parceros carecen de narrativas que den cuenta de sus "fugas", de los resortes que las impulsan y las implicaciones que arrastran, limitados a contar una y otra vez sus anécdotas a la manera de una aventura incesante. Sin embargo, su actuación está allí, desafiante, patente en los contingentes de jóvenes embriagados por su oferta de poder.

No es un héroe urbano, una especie de víctima empujada por los desfavorables engranajes en que el torbellino de la vida lo paró. Frente al cuadro de la muerte colombiana sería injusto reivindicar cualquier forma de agencia social preñada de violencia, mucho más si ella se realiza con la inconsciencia propia del pequeño poder particular. Con todo, si resulta ilegítimo el intento de heroizar la pandilla, también resulta nefasta la pretensión de achatarla en una empobrecida expresión de la crimi- nalidad. Los parceros delinquen, mantienen diversas formas de hurto y ejercen una violencia tenaz sobre aquel que se interpone en la satisfacción de sus ansias de hedonismo. No obstante, sus abusos económicos están lejos de los propios de la banda profesional y sus violencias se igualan en intensidad con las de otros tantos actores regados aquí y allá.

De manera que ni el héroe ni el criminal. Entre uno y otro, más bien, el pandillo se erige en testimonio elocuente del desafío enrostrado por las turbulencias en que nace el siglo XXI: evidencia la mundialización de los esquemas de identidad y sus armaduras de sentido —el núcleo duro de la experiencia pandillera se repite igual en ciudades latinoamericanas, pero también lo hace en múltiples rincones del planeta-; mostrando uno más de los rostros apabullantes y siniestros de la globalización deja ver la emergencia de renovados actores y su construcción de un lugar en lo público desde la irreductible afirmación de un estilo de vida; marca las transformaciones del conflicto, ahora tantas veces envuelto entre las urgencias de la vida puramente local y cotidiana; rotula las tensiones de una era consumida entre la obsesiva búsqueda de sensualismo 
y la atribulada fragmentación institucional. En suma, la pandilla se instituye en sujeto donde hablan las texturas de la ciudad contemporánea. Sólo recorriendo este atajo se revela su alma, más allá de la horrenda costumbre de resolver el conflicto mediante el procedimiento de la muerte.

Las pandillas proclaman la precariedad de lo social, denuncian la escisión de las prácticas sociales y las formas de constitución de la identidad: por ello, los pandillos viven en un afuera, remisos a las exigencias de una vida colectiva concebida bajo la rúbrica del tiempo futuro. Para el pandillero, por el contrario, el tiempo se desconecta de cualquier coordenada que esté un paso más allá de sus ritmos biológicos y sus afanes sensualistas, lejos de la regularidad social inscrita en las rutinas de estudiar, trabajar, hacer familia. No en vano lo sagrado se le agota en la máxima del territorio es sagrado y no gratuitamente su ritualidad está en la muerte, en el modo como densifican los sepelios y codifican la fidelidad a sus muertos.

Empero, la misma pulverización de lo social revelada por el pandillero desde abajo, desde el barrio de miseria, raciones de limpieza. Ya las múltiples formas de movilización de los vecinos, desde la queja desesperada hasta la avanzada de los encapuchados, ponen al descubierto la precariedad de la mediación social en la construcción de la más elemental convivencia. Pero será frente a la operación de limpieza que lo instituido estalle en pedazos. Ante sus sanguinarios procederes recubiertos de mutismo -el silencio que arrastran sus ejecutores pero también el silencio de la autoridad respecto a su actuación-, la cultura y el símbolo ceden aniquilados ante la abdicación de un andamiaje institucional que ha renunciado a la fibra más íntima de su fundamento.

La pandilla y la limpieza son adversarias en las gueras de pavimento, pero idénticas y paralelas en sus formas de desciframiento. Ambas se alimentan de una institucionalidad de la que, no obstante, permanecen al margen, convertidas en formas parásitas de lo social. Las dos carecen de algún discurso legitimatorio de su existencia y su accionar: son el cuerpo social en marcha desprovisto de signo alguno que no sea su imposición de máquina de guerra. Frente a ellas la cultura se detiene vacilante y muda,

pese a que ambas develan, como nadie más lo hace, el abismo sobre el que se erige la vida colectiva en la ciudad. Los unos ensañados con los vecinos, los otros con los jóvenes, arrancan a la convivencia y la justicia su más elemental pálpito ético. A cambio de ello las hablas de unos y otros se hunden en la administración del miedo, gozosos de su condición de artefactos de provocación del pánico urbano.

\section{Bibliografía}

Andrade, Xavier, 1994, "Violencia y vida cotidiana", en Julio Echeverría y Amparo Menéndez, Violencia en la región andina. El caso de Ecuador, Flacso, Quito.

Bourgois, Philippe, 1995, In Search of Respect. Selling Crack in El Barrio, Cambridge University Press, Londres.

Briceño-León, Roberto, 2003, en Memorias del seminario "Jóvenes y policías en Latinoamérica", 2 y 3 de diciembre de 2002, CLACSO, Quito, en prensa.

Castillo, Héctor, Sergio Zermeño y Alicia Ziccardi, 1988, Juventud popular y bandas en la ciudad de México, México, mimeógrafo.

Chabedi, Mark, 2002, Destin-LSE. Crisis States Programme's. Second International Wokshop, 23-24 de abril, Bogotá, mimeógrafo.

Comuna 8, s.f., Informes locales al Concejo de Neiva, mimeógrafo.

DANE, 1993, Encuesta nacional de calidad de vida, Bogotá.

__, 1995, Encuesta nacional de calidad de vida, Bogotá.

Equipo de Reflexión, Investigación y Comunicación (ERIC) de Honduras, Instituto de Encuestas y Sondeo de Opinión (IDESO) de Nicaragua, Instituto de Investigaciones Económicas y Sociales (IDIES) de Guatemala e Instituto Universitario de Opinión Pública (IUDOP) de El Salvador, 2001, Maras y pandillas en Centroamérica, Uca, Managua.

Formar Ciudad, 1995, Plan de desarrollo económico, social y de obras públicas para Santa Fe de Bogotá. 1995-1998, decreto núm. 295, 1 de junio.

Fundación Social Barranquilla, 1998, Barranquilla: en busca de una segunda oportunidad sobre la tierra, Fundación Social, Barranquilla.

Funke, Hajo, 2000, "Desintegración social, extremismo de derecha y violencia xenófoba en Alemania", en Globalización de la violencia, Colibrí, México.

García, Carlos Iván, 1998, En algún lugar parcharemos. Normas y valores de los parches de la localidad 11, Observatorio de Cultura Urbana-Tercer Mundo, Bogotá. 
Gomezjara, Francisco, et al., 1987, Las bandas en tiempos de crisis, Nueva Sociología, México.

González-Placencia, Luis, 1999, La inseguridad subjetiva en la Ciudad de México. Estudio exploratorio acerca de la actitud de los capitalinos frente a la seguridad pública en el Distrito Federal, Fundación Rafael Preciado HernándezEstudios de Seguridad, Justicia y Derechos Humanos, México.

Gouëset, Vincent, 1998, Bogotá: Nacimiento de una metrópoli. La originalidad del proceso de concentración urbana en Colombia en el siglo XX, Tercer Mundo-Observatorio de Cultura Urbana-Cenac-Ifea-Fedevivienda, Bogotá.

Homies Unidos-Instituto Universitario de Opinión PúblicaRadda Barnen de Suecia-Save the Children, 1998, Solidaridad y violencia en las pandillas del gran San Salvador, Uca, San Salvador.

Instituto Nacional de Medicina Legal y Ciencias Forenses, 1992-2000.

Kennedy, David, Anthony Braga y Anne Piehl, 2003, "Reducing Gun Violence. The Boston Gun Project's Operation Cease Fire", en María Victoria Llorente y Mauricio Rubio, Elementos para una criminología local, Alcaldía Mayor de Bogotá, Bogotá.

León, Fabricio, 1984, La banda, el concejo y otros panchos, Grijalbo, México.

Liebel, Manfred, 2002, Pandillas juveniles en Centroamérica o la difícil búsqueda de la justicia en una sociedad violenta, mimeógrafo.

Medina, Carlos, 1990, Autodefensas, paramilitares y narcotráfico en Colombia, Documentos periodísticos, Bogotá.

Monod, Jean, 2002, Los barjots. Etnología de bandas juveniles, Ariel Social, Barcelona

Observatorio de Cultura Urbana, 1977, Seguridad y violencia en Santafé de Bogotá, Instituto Distrital de Cultura y Turismo, Bogotá.

Ortiz, Carlos Miguel, 1985, Estado y subversión. La violencia en el Quindio, años 5o, Cerec-Cider, Bogotá.

Perea, Carlos Mario, 1996, Juventud, cultura y narcotráfico. Dos estudios de caso: Tello y Bogotá, Banco Mundial-Viceministerio de la Juventud, Bogotá.

$\ldots$ _ 2003, "El que la debe la paga. Pandillas y violencias en Colombia”, en Memorias del seminario "Jóvenes y policías en Latinoamérica", 2 y 3 de diciembre de 2002, CLACSO, Quito, en prensa.

Pérez, Diego, y Marco Raúl Mejía, 1996, De calles, parches, galladas y escuelas, Centro de Investigación y Educación Popular (CINEP), Bogotá.

Pizarro, Eduardo, 1996, Insurgencia sin revolución. La guerrilla en Colombia en una perspectiva comparada, Tercer Mundo-Iepri, Bogotá.

Por la Bogotá que queremos, 1998, Plan de desarrollo económico, social y de obras públicas. 1998-2001, acuerdo núm. o6, 8 de junio.
Reguillo, Rossana, 1995, En la calle otra vez. Las bandas: identidad urbana y usos de la comunicación, Iteso, Guadalajara.

Roché, Sebastián, 2003, "La estabilidad del crimen en Francia: Violencia juvenil, respuestas públicas”, en María Victoria Llorente y Mauricio Rubio, Elementos para una criminología local, Alcaldía Mayor de Bogotá, Bogotá.

Rojas, Camilo, 1996, La violencia llamada limpieza social, CINEP, Bogotá.

Rodgers, Dennis, 2000, Living in the Shadow or Death: Violence, Pandillas and Social Disintegration in Contemporary Urban Nicaragua, tesis doctoral, Cambridge, Londres, mimeógrafo.

—, 2002 , "Dying for It: Youth Gangsterism in Urban Nicaragua, 1997-2002”, en Destin-LSE. Crisis States Programme's. Second International Wokshop, 23-24 de abril, Bogotá, mimeógrafo.

Romero, Mauricio, 2000, "Democratizacion política y contrarreforma paramilitar en Colombia”, en Violencia colectiva en los países andinos, Bulletin de L'Institut Français d'Études Andines, t. 29, núm. 3, 2001, Instituto de Estudios Andinos (Ifea), Lima.

Salazar, Alonso, 1990, No nacimos pa' semilla, Región-CINEP, Bogotá.

—_ y Ana María Jaramillo, 1992, Medellín. Las subculturas del narcotráfico, CINEP, Bogotá. La solidaridad violenta de las pandillas, Instituto Universitario de Opinión Pública, San Salvador.

Segovia Guillermo, 1994, La violencia en Santafé de Bogotá, Ecoe, Bogotá.

Subdelegación de Desarrollo Social, 1987, Informe de investigación, delegación Álvaro Obregón, México, mimeógrafo.

Téllez, Mireya, 1995, Las milicias populares. Otra expresión de la violencia social en Colombia, Rodríguez Quito, Bogotá.

Uribe, María Victoria, 1990, Matar, rematar y contramatar. Las masacres de la violencia en el Tolima. 1948-1964, CINEP, Bogotá.

—— y Teófilo Rojas, 1996, Enterrar y callar, Comité Permanente por la Defensa de los Derechos Humanos, Bogotá.

Urteaga, Maritza, 2000, "Formas de agregación juvenil”, en José Antonio Pérez Islas (coord.), Jóvenes: una evaluación del conocimiento. La investigación sobre juventud en México, 1986-1999, vol. II, Instituto Mexicano de la Juventud, México.

Valenzuela, José, 1988, ¡A la brava ese!, El Colegio de la Frontera Norte, México.

Whyte, William, 1971, La sociedad de las esquinas, Diana, México. 